Elahe Helbig*

\title{
A New "Vision": Early Works of Ahmad Aali and the Emergence of Fine Art Photography in Iran (1960s-1970s)
}

DOI 10.1515/asia-2016-0047

\begin{abstract}
This article explores the emergence of fine art photography in Iran during the 1960s and 1970s, bringing to the fore the significance of Ahmad Aali and his early photographic works for this transformation. It sheds light on the confluence of the main trajectories that paved the way for the formation of fine art photography in Iran, firstly by exploring historical practices of photography, secondly by addressing the influences of transforming political and social agendas after World War II on photographic developments, and finally by underlining the involvement of photography in the artistic sphere of that time. Central to the latter is Aali's contribution to theoretical discourses about photography as an artistic medium and the major role he played in the first photographic exhibitions in art spaces. In that perspective, this article argues for the pivotal role of Ahmad Aali in bridging the gap between photography and art for the first time in Iran's long history of photography. It analyses Aali's photographic works exhibited during the 1960s and 1970s to comprehend the circumstances of the emergence of fine art photography in Iran, and does so by discussing the modernist aesthetics in photography that emerged at the time. Going beyond Aali's regional importance, it examines his conceptual approaches to overcoming the 'static realism' and the limitations of the medium. Aali's novel photographic concepts of space and time that emerged therefrom should be accorded their full autonomy and uniqueness in the (re-)writing of a narrative of art history on their very premises. This article thereby seeks to support a critique of the narrow epistemological boundaries of the discipline of art history and its resulting marginalization of locally developed art forms and concepts.
\end{abstract}

Keywords: Ahmad Aali, Iranian modernism, sequential photography, modernist photography, photographic concepts of space and time

*Corresponding author: Elahe Helbig, Teaching Assistant, University of Geneva, 22, Boulevard des Philosophes, CH-1211 Geneva 4, Switzerland. E-mail: Elahe.Helbig@unige.ch 
The passing of time and its invisible movement is an issue that has engaged me from the outset of my work; by putting a number of photos alongside each other, I would gain a mental relationship of their continuity with another concept in another space-time ${ }^{1}$ - Ahmad Aali

\section{Introduction: Understanding photography Anew}

In 1965, the pioneer and artist Ahmad Aali (born 1935) bridged the gap between photography and art; for the first time in Iran's long history of photography he demanded that the medium of photography be located within the artistic sphere. In the introductory text to his exhibition catalogue for the art gallery Talar-e Iran (later Talar-e Ghandriz), Aali explored the aesthetic possibilities inherent to photography as a medium of visual art (Figure 1). He claimed that the "thoughts and emotions in photography are inseparable from technique, technical expertise and execution." ${ }^{2}$ In that sense, Aali dislocated photography from the hitherto prevailing understanding of it as an Ab-Bild ${ }^{3}$ (likeness) of nature and reality. He reinvigorated and redefined the relation between the appearances of the external world and the subjectivity and the sensibilities of the artist, stating: "I want to intervene in nature and its realities". ${ }^{4}$ This statement brings to the fore Aali's critical attitude towards the conventional forms and traditional practices of photography as a medium that had been used up to that time in Iran principally for documenting and reminiscing.

Far from simply introducing his photographic works, Ahmad Aali's short essay (re-)explored and enlarged the confines of photographic practices in Iran. It put forward an overall novel conception of photography, one that far exceeded the expectations of the medium when it was introduced to Iran in 1842 as nothing more than a technical recording device. ${ }^{5}$ By 1965, Iranian

1 Mohajer 2016: 367. Translation slightly modified.

2 Aali 1965: unpaginated. Touraj Hamidain also published Aali’s short essay in a monograph in the context of the retrospective on Aali's photographic works held in 2010 in the gallery Mah-e Mehr in Tehran. See Hamidian 2010: 15-16 in Persian, 245-246 in English.

3 I borrow this term from the exhibition catalogue "Das Bauhaus: allesistdesign", where it is applied to the photographic movement 'Neues Sehen'. There as here, the notion is crucial to the explanation of a fundamental rupture with a prevailing understanding of photography. See Kries/Kugler 2015: 340.

4 Aali, 1965, in Hamidian 2010: 246.

5 See Livingstone 1997: 7. He calls to attention Duane Michals' essential “[...] demands of photography that far exceed the expectation for the medium when it was first invented in the 1830 s as a way of recording appearances." 

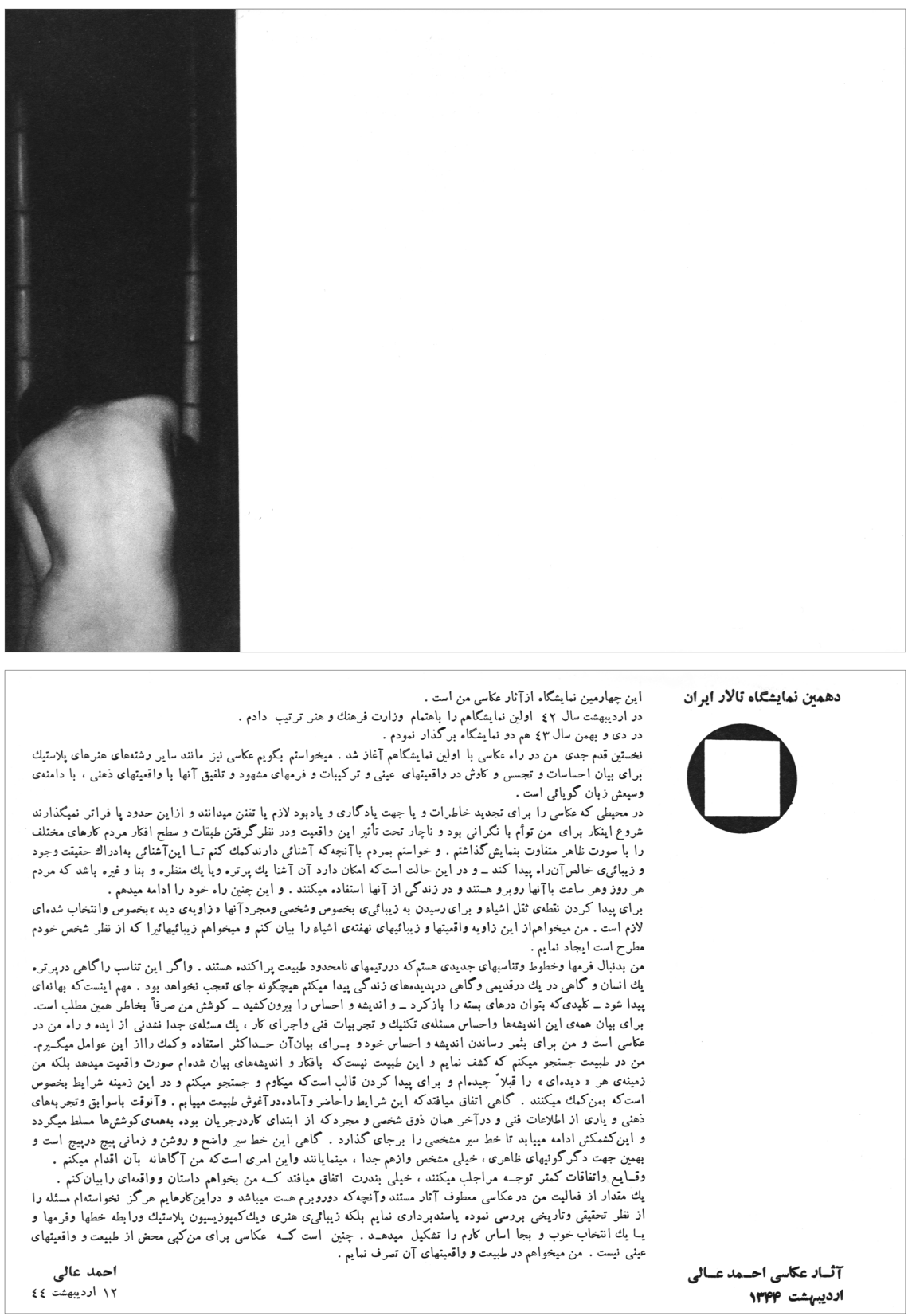

Figure 1: The catalogue of the exhibition of Ahmad Aali at the Talar-e Iran. On the front page, there is a photograph of Ahmad Aali, while his short essay is published on the rear page. 
photography had already passed through various spheres of application. Within the context of the social, political and cultural shifts of modern Iranian history - the Constitutional Revolution, resignation, coup d'état, dynastic change, the National Front, the World Wars and geopolitical power struggles - photographic concepts and modes of representation had found themselves in continuous flux. Nevertheless, at no point had photography been understood as an artistic medium. Even photographers themselves had never once advanced a claim to being engaged in the visual arts; despite some creative uses of photography. ${ }^{6}$

Given this historical background, Ahmad Aali, perceiving the need to formulate a novel definition of photography in modern Iran, partook in a lively debate with Mansour Ghandriz (1936-1966), the co-founder of the art space Talar-e Iran and a prominent figure in modern Iranian art. $^{7}$ Ghandriz and Aali agreed on the subjectivity and the solipsism of aesthetic of photography, as of any artwork, Aali however wanted to spark a discussion about photography as art within the artistic currents of his own time. The art historian Turaj Hamidian was the first to recognise, retrospectively, the fundamental importance of Aali's introductory text to the new understanding of photography by defining it as "akin to a manifesto". 8 This short essay was indeed the first and the only manifesto of fine art photography in Iran. It lines up with the few other manifestos that had been published between the 1950s and 1970s in Iran. These expressed the struggle against established canons in art practices, fought for artistic self-determination and advocated modern forms of art. ${ }^{9}$ Together with Aali's later essays, interviews and art critiques, his ground-breaking Manifesto explains the photographic concepts and the essence of the thoughts and ideas that the artist, for the most part, went on to pursue thereafter. More importantly,

\footnotetext{
6 For example, Bahman Jalali published a set of photographs that reveal creative and experimental aspects of Iranian photography during the Qajar period. See Jalali 1998.

7 Ahmad Aali recalls the initiation of the catalogue text as well as his lively discussion with Mansour Ghandriz at a roundtable discussion on 5 November 1992. This roundtable was organized by the Kelk Magazine and the panellists included Mina Nouri, Morteza Momayez, Yahya Dehghanpour and Mehran Mohajer. The conversation provides a profound insight into the artistic endeavour and early works of Ahmad Aali. Furthermore, the discussion touches on the role of photography within the artistic currents of the1960s. See "Conversation with Ahmad Aali" 1997: 483.

8 Hamidian 2010: 246.

9 See Behpoor 2014. He examines two manifestos that were among the earliest in modern Iranian art: the "The Nightingale's Butcher Manifesto" (in Persian: Sallakh-e Bolbol), published in 1951, and the "Volume and Environment II", published in 1976.
} 
however, these texts shed light on the contemporary discourses about photography as part of, and belonging to, the artistic movements of the 1960s and 1970s in Iran.

Having started his artistic career as a painter, Ahmad Aali took his first steps in photography in 1958. Because of the lack of academic training in photography, he approached the medium through experiments and independent research. Before even considering the practical aspects of photography, Aali spent almost two years exploring photographs from monthly photography journals and periodicals, publications and photo albums, and analysed their composition, the interplay between light and shadow and their aesthetic features. ${ }^{10}$ In his quest for a new aesthetic, he engaged with the European and American modernist movements that had marked the early twentieth century. Aali became familiar, in particular, with the photographic movement 'Neues Sehen', including its two major figures, László Moholy-Nagy (18951946) and Man Ray (1890-1976), as well as the 'f/46' group and its prominent photographer Edward Weston (1886-1958). These and other trends of modernism in photography differentiated photography from other visual media, particularly painting. Accordingly, they disagreed with nineteenth and earlytwentieth-century photographic styles, pictorialism above all, that sought to develop a photographic aesthetic modelled on painting. On the contrary, modernist photography exploited, rather than obscured, the essentially mechanical and technological aspects of the medium. Whilst interacting with broader modern art movements, like Abstraction, Constructivism and Surrealism, they delved into the potential embedded in such aspects to extract an autonomous aesthetic language for photography. This language emphasized formal qualities and was constituted by straightforward, unadulterated images of modern life. It was a language that reflected the emerging urbanization and 'new' dynamic of everyday life. ${ }^{11}$

Why did Ahmad Aali draw his inspiration precisely from these photographic tendencies in his early experiments with the medium? For one thing, because the fundamental principles established in modernist photography were crucial

10 Mohajer 2016: 369.

11 Most historians date the beginnings of modernism in photography to the 'Photo-Secession', a movement founded by Alfred Stieglitz in 1902. Modernist photography in the West encompasses photographic trends from roughly 1910 until 1950. David Campany explores the principles of modernist photography and its influence thereafter. He points out that the characteristics of modernism in photography differ from those in painting. See Campany 2005: 18. See also Koschatzky 1993: ch. 16. 
for further photographic developments, as post-war American photography forcefully demonstrates. Moreover, these principles tied in with the underlying vision of those artistic currents of the 1960s that Aali pertained to; for example, the artistic group that founded Talar-e Iran. These artistic groups pursued experiments with modernist aesthetics and different styles of modern art similar to those Aali envisioned for photography. Most significantly, however, this modernist language was an appropriate means for breaking away from the rigid conventions and practices that had been established throughout the history of Iranian photography.

The early photographic works of Ahmad Aali - portraits, landscape vistas, urban and architectural scenes - reveal an aesthetic that was based on precisely exposed images of forms and objects encountered in nature. Aali was primarily concerned with the technical and conceptual aspects of photography, and thus the subject became secondary for the artist. This manifests Aali's critical attitude towards an aesthetic in Iranian photography that had started to filter through towards the end of the 1950s. This trend had used techniques, like modifying photos through soft focus, special filters and lighting, and the post-processing of photographic negatives. By contrast, Aali paid close attention to the fundamental principles of modernist photography in his early works: these included transgressing the restrictive limits of optical vision, transforming perspectival rules through steep views in low- and high-angle shots, incorporating the structural lines of nature and urban scenes in image landscapes, juxtaposing shadow and light, breaking the bounds of conventional landscapes and taking close-ups of single textures or repeated motifs (Figure 2). Aali was also interested in the unconventional techniques and artistic strategies of modernist photography; for example, image inversion procedures, multiple exposures, photo-collage, photomontage, and combining photographs with other artistic media (Figure 3). ${ }^{12}$

However, Ahmad Aali always sought to go beyond established and traditional forms. In engaging photography in an autonomous and self-contained fashion, he developed novel concepts that were pioneering for his time. Therein, Aali aspired to overcome the 'static realism'13 of photography: the

12 Ahmad Aali's oeuvre has for the most part been published in two monographs. His photographic works are untitled, Aali only gave indications as to the date and site of the photographs. These publications reveal illuminating insights into his photographic concepts and artistic strategies. See, "Ahmad Aali. Selection of Works 1961-2009”, 2010; “Ahmad Aali. Selection of Paintings and Photographs 1953-2014”, 2016.

13 Rainer Wick used this term in discussing the serial photography of Kurt Kranz. See, Wick 1991b: 160 . 


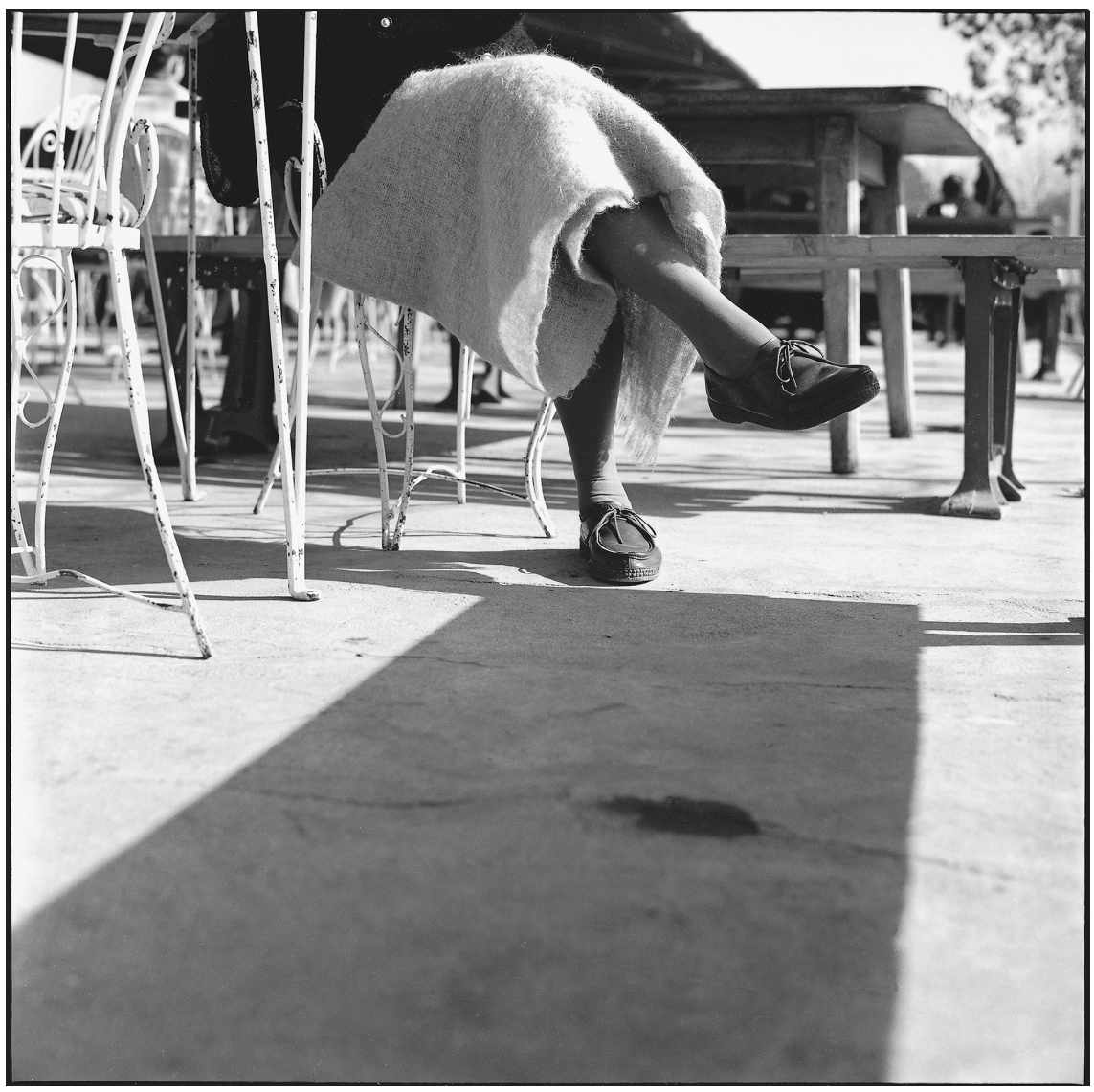

Figure 2: Ahmad Aali, Tehran, 1962, silver gelatin print, courtesy of the artist.

seemingly essential limitation that photography can only ever reveal a particular point of the unfolding flow of time on a given spatial surface. By taking photographic series of the same space at timed intervals or from slightly modified angles, and juxtaposing them to create interlinking contexts, Aali evokes a multitude of possible images that render the idea of an isolated space-time obsolete. In exposing objective reality to subjective interpretability, photographic singularity dissolves in favour of temporal continuity and spatial infinity.

In what follows, I will examine the cultural landscape of post-World War II Iran, in the context of which the spheres of application of photography had been defined anew. In doing so, I outline the confluence and interaction of various 


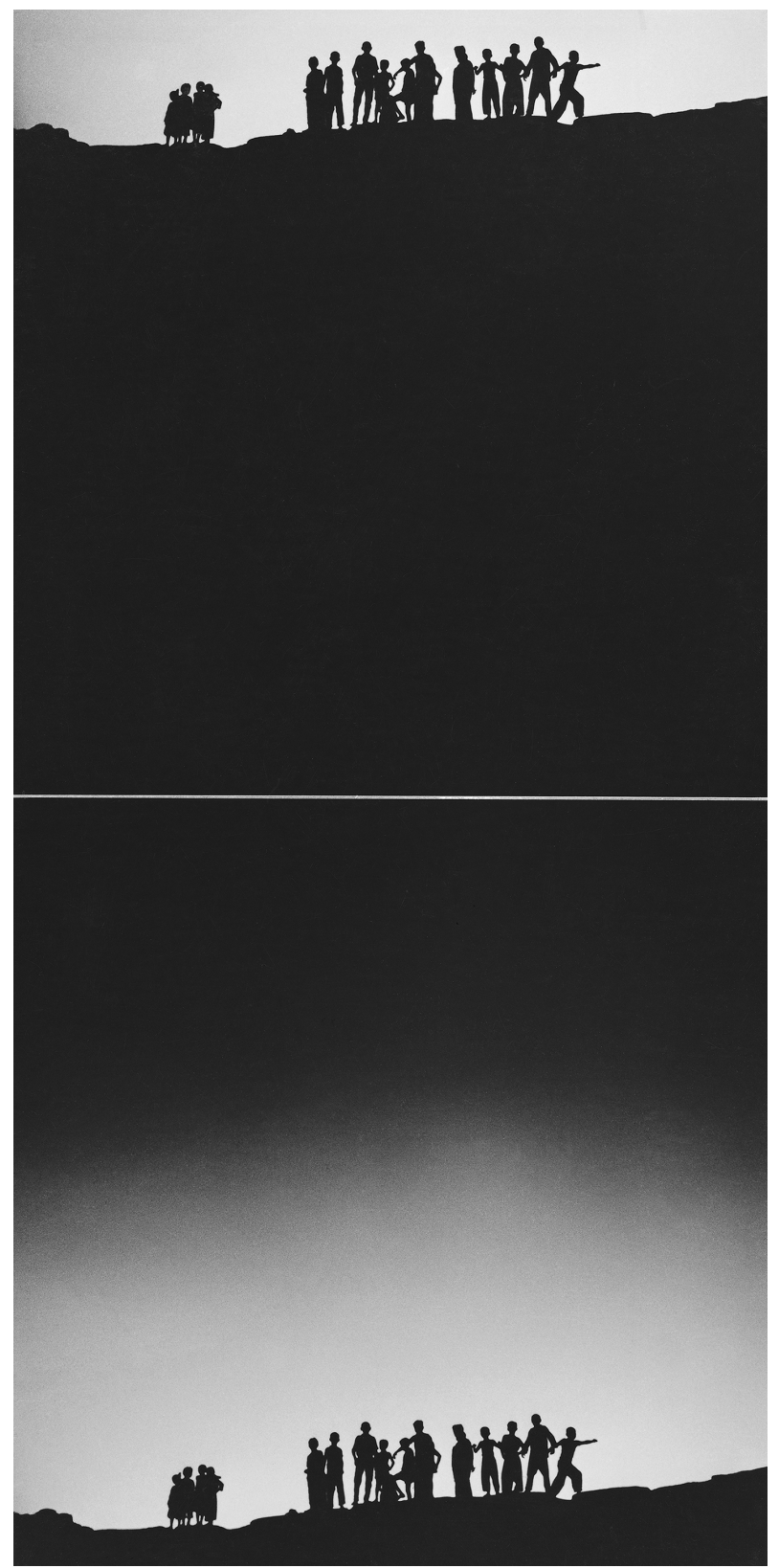

Figure 3: Ahmad Aali, Masjed Solyman, 1963, silver gelatin print, courtesy of the artist. 
trajectories - developments internal to the history of photography, to official cultural and social policies and to the artistic movements of the time - which ultimately gave birth to fine art photography. The foundational significance of Ahmad Aali in this process, manifested in his theoretical discourses and his photographic works, was twofold: he was the pioneer of fine art photography and he heralded modernist trends in Iranian photography. Given Ahmad Aali's importance, I examine key works he exhibited during the 1960s and 1970s in Iranian art spaces and in exhibitions of Iranian modern art outside Iran. The discussion of Aali's works tracks and explains the artistic strategies and techniques that were emerging in Iranian fine art photography and in the modernist aesthetics in photography that developed congruently.

However, the significance of Ahmad Aali, I argue, goes far beyond the geographical boundaries and specific historical timeframe of Iranian photography. Aali's independently elaborated photographic concepts of time and space - literally and allegorically embedded in his serial photographs from the 1960s and 1970s - reveal similarities with, but also divergences from, photographic strategies outside Iran. On a global scale, they were novel for the photographic landscape of the 1960s and continue to embed innovative approaches in photography. Yet, Aali's fundamental contribution to photography does not have the place it deserves in the world history of photography, or in canonical art history for that matter. This lends support to Robert Nelson's critique of the discipline of art history for its restrictive epistemological boundaries. Art history spatially and temporally maps global culture on the basis of teleological narratives that proceed from Euro-American centres of classification. In line with Nelson's critique, this article contributes to the (re-)writing of art history to dissolve its canonical boundaries by giving artists like Ahmad Aali and their locally developed concepts a firm standing within the arthistorical narratives. ${ }^{14}$

\section{A medium in transition: A historical perspective}

The 1960s and 1970s were the crucial decades in the emergence of fine art photography in Iran. It was born out of the confluence of different trajectories: social and political changes that gave an impetus to broadening novel photographic practices and photography's engagement with current artistic movements that challenged

14 Nelson 1997. 
conventional modes of representation. How did the historical development of this visual medium unfold and, more importantly, how was the gap between photography and art bridged after World War II in Iran?

In its long history, photography's spheres of application and modes of representation in Iran had largely developed in line with political agendas, generally including the processes of modernization, of nation-building and the foundation of a nation state. Photography was employed in formulating an official narrative of these events and, as history would have it, in establishing a responsive counter-narrative.

When photography was introduced to Iran in 1842, its use was mainly restricted to the court and the elite. ${ }^{15}$ However, towards the end of the nineteenth and beginning of the twentieth century, photography played a dominant role in the visual politics of Iran. The turn of the century coincided with a turn in photography towards a mass medium, a process of democratization in which public photographic studios played a crucial role. Thus transformed, photography enforced and shaped the vision of a coherent nation during the Iranian Constitutional Revolution (1905-1911). ${ }^{16}$ Along the historical path to the Pahlavi I era (r. 1925-1941), state policy focused on visualizing and disseminating the manifestations of a modern nation and its citizens. Some of the modernization policies introduced by Reza Shah (1878-1944) reinforced the significant role that public photographic studios had occupied in broadening the reach of the medium: for example, the law of birth registration in 1923, the implementation of mandatory identification pictures for birth certificates and other official documents in 1926 and the mandatory unveiling of women in 1934. These laws increased the demand for family photographs. ${ }^{17}$ The commercialization of photography thus not only popularized the medium but also fortified its canons, forms and modes of representation born in public photographic studios.

15 The history of Iranian photography, its beginnings and its manifold developments has been the subject of research since the 1970s. For a detailed bibliography covering the first hundred years of the history of Iranian photography, see for example Bonetti/Prandi/Mohammadi Nameghi 2013; for a chronology of the most significant events during this first century, see Tahmasbpour 2013.

16 For a discussion of the visual politics during the Constitutional Revolution (1905-1911) and the role of photography in the processes of nation-building, see Sheikh 2010 and Helbig 2016 (forthcoming).

17 Tahmasbpour 2013: 12-13. The surging number of family photographs with women was important in the popularization of the medium. See Motarjemzadeh 2011: 118. For the history of photography during the Pahlavi I period, see also Manouchehrzadeh 2008: 24-29; and Motarjemzadeh 2013: 67-69. An overview of the important occurrences is provided by Hamidian 2007: 85-90. 
Alongside the political agenda of the Pahlavi I era, there was a surge in press photography to the extent that photo journalism was born as an independent profession. ${ }^{18}$ Photography, just like film, painting and design, started being officially regulated, and the first professional associations were founded; for example, the Corporation of Iranian Photographers, which was founded in 1925 and continued its work after the Second World War in 1948. Further important associations included the Press Council in 1946, an affiliate of the International Press Association, and the National Society for Photography in Iran, founded in $1950 .^{19}$

Up to this point, photography had been understood as a medium of reminiscence and remembering, recording and documenting. However, the emergence of critical documentary and press photography in response to the political events of the 1950s put the use of the medium in public visual space through a significant transformation. Though traditional uses of photography were carried on in public photographic studios, new tendencies in non-commercial photography emerged. In respect of portrait and landscape, photographers started experimenting with form, composition and different aesthetic ideals. Similarly novel tendencies shone through in photographic documentations of Iran and its people. ${ }^{20}$ In addition to photography being used in advertisements, "non-applied" and creative photographs started to appear in magazines and in the press. In general, the professionalization of the field of commercial and press photography was a crucial catalyst to the emergence of novel photographic practices and spheres of application. ${ }^{21}$ Motarjemzadeh describes the first photographs of this kind - published in the magazine Ferdoussi in 1956 - as the "appearance of an exception" 22 in the Iranian press. Thereafter, the press,

18 Images of milestones of modernity, such as the inauguration of a dam, the first group of pilots, events in which women participated and photographs of national sites, were central in articulating the image of a modern Iran. The Institute for Political and Interantional Studies in Tehran possesses an extensive collection of photographs of this kind, many of them taken by Mohammad Jafar Khadem. Regarding a discussion of the cultural politics pursued by Reza Shah Pahlavi, compare for example Grigor 2009: ch. 1. For a discussion of the construction of a national identity by reference to the cultural legacy of Iran, see Rizvi 2007.

19 Tahmasbpour 2013: 13; Hamidian 2007: 86.

20 This started with Mehdi Seifolmolouki and later culminated in the works of Nasrollah Kasraian (born 1944), an internationally renowned photographer.

21 Most journals had already started to be illustrated with photographs from the 1940s onwards, and some even before that, prominently including, Iran-e Emruz (Iran Today) and Iran-e Bastan (Ancient Iran).

22 Motarjemzadeh 2011: 91. He points e. g. to photographs of urban landscapes by Hadi Shafaieh. 
especially magazines such as Tamasha, Roudaki, Cinema 53, Zan-e Rouz, and Negin, provided a platform for creative photography. This included works by artists, architects, film producers, and amateur photographers, who were questioning traditional conventions and experimented in applying new aesthetic values.

As a result of photography's growing popularity, photo journals and magazines devoted to photography started being published. These included 'Akkasi (1966-1967), Tasvir (May 1972-September 1974) and Photo (1974-1975). Magazines of this kind covered a broad range of photographic topics: new technologies, contemporary trends, photographic education, and well-known international photographers and their works. Photography having become a subject of notice to society, radio broadcasts and television programmes also started being devoted to the medium. They discussed technical details but also the aesthetic of this visual medium. All this significantly enhanced the reach of photography in society and established it within the framework of cultural activities. In the context of these developments, the first competitions for amateur photographers were organized. These were initially hosted by the cultural centres of foreign embassies - by the Iran-Soviet Cultural Society (VOKS) in 1944 and in 1948, and by the French Cultural Society in 1952 which had become important venues for cultural events in Iran after World War II. Equally significant for the promotion of creative and "non-applied" photography were exhibitions, such as the one organized by the Club Mehregan in 1955. This featured both amateur and professional photographers. ${ }^{23}$

The ever-growing prevalence of photography increased the need to take education in it beyond public photographic studios and to establish it as an academic subject of study. To this end, photography was introduced in 1970 first to the Faculty of Fine Arts of Tehran University - although associated with graphics - and thereafter to the College of Decorative Arts in Tehran. ${ }^{24}$ Further, the National Iranian Radio and Television, founded in 1968, established a photographic laboratory for Seda va Sima (Voice and Image). Lastly,

23 Manouchehrzadeh 2008: 32. During the 1950s, Bashgah-e Mehregan organized several exhibitions, portraying both modern art and academic art. It was a lively site for discussing, debating, and articulating theoretical positions on modernism.

24 Six years after the foundation of the University of Tehran in 1936, the Faculty of Fine Arts was set up under the director Andre Godard. The faculty had followed the principles of the Parisian Beaux-Arts, and thus established the academic subjects of architecture, painting and sculpturing. The School of Decorative Arts was founded in 1961. 
photography became part of the curriculum at the Advanced School of Television and Cinema, founded in $1969 .{ }^{25}$ Although the significance of academic training for the promotion of fine art photography has not yet been addressed in scientific investigations, there can be no doubt that it was paramount. In contrast to the conventional forms taught via traditional channels, the academic teaching of photography was more concerned with its aesthetics, experimental aspects, contemporary trends and the world history of the medium. ${ }^{26}$ Moreover, it put photography into immediate correspondence with other artistic subjects and so it was primarily art and architecture students that attended the photographic classes of the Tehran University and the College of Decorative Arts. ${ }^{27}$

The advances in photographic education went hand in hand with fundamental transformations in the academic teaching of the arts, in cultural activities and artistic practices. Following the 1953 coup d'etat, which ousted the nationalist government of Prime Minister Mohammad Mossadegh (1882-1967), there came a period of growing stability. The consolidation of the reign of Mohammad Reza Shah Pahlavi (r. 1941-1979) and the drastic surge in state revenue from oil exports during the 1960s and 1970s created the ideal conditions for the state to implement a comprehensive cultural policy. Its aims were to form a national identity for modern Iran, one that, though based on Western ideals, would be conscious of its cultural heritage and, relatedly, to establish Iran as a cultural

25 Motarjemzadeh also mentions a two-year training in film and photography, organized by the Office of Fine Arts in collaboration with the University of Syracuse in 1954. However, he does not provide any further information on this. See Motarjemzadeh 2011: 71. It was only after the Islamic Revolution, in 1984, that photography was introduced as an independent subject of study at Iranian universities. For further information see Manouchehrzadeh 2008: 217.

26 Ahmad Aali taught photography at the Advanced School of TV and Cinema from 1970 until 1973; Hadi Shafaeih was engaged as a lecturer at both of these university institutions; after completing his studies in photography in France, Kamran Adle established the photographic laboratory for Seda and Sima; and thereafter Bahman Jalali and Yahya Dehghanpour taught at different educational institutions.

27 In the context of photography's correlating with architecture, Hamidian mentions one of the first photography exhibitions held at the Faculty of Fine Arts. This displayed experimental photographs by two of its students. He further indicates that many students of architecture had experimented with photographic ideas and implemented innovative concepts during the 1960s and 1970s. These included Reza Deghati (born 1952), who now is a prominent photojournalist. The photographic works of these architects had also been exhibited on various occasions: for example, those of 'Ata Omidvar (born 1946) were exhibited in the Iran House in Paris in 1976. Hamidian 2007: 93-95, 97-98. 
centre of significance on the geopolitical scale. ${ }^{28}$ A milestone in the enforcement of these cultural agendas was the centralization of culture: hitherto scattered state organs and their independent, fragmented cultural policies were unified under the head of the Higher Council for the Arts in $1969 .{ }^{29}$ In line with this centralizing policy, other cultural institutions, centres for cultural education and museums were founded.

The official cultural institutions provided a site for local art and supported cultural practices. Photography benefited therefrom through various channels, such as scholarships for the academic study of photography in Europe, publications of photo books on Iranian cultural heritage, invitations of internationally renowned photographers on political or cultural occasions, and organizations of photography exhibitions. It was in this context that, the photography exhibition "The Footprints of the Centuries", encompassing a total of one hundred and fifty photographs by Hadi Shafaieh (born 1923), was organized. It was first hosted in the Golestan Palace and later staged in Switzerland - Bern, Geneva and Zurich - and in Italy. The exhibition attracted the interest of the press and various art critiques were published on it, for instance by Hamid Notghi and Maurice Bernard. ${ }^{30}$ The pinnacle of state-organized photographic exhibitions is found in the Tehran Museum of Contemporary Art (TMoCA). Inaugurated on 14 October 1977, the TMoCA had its own photographic department. This held an exceptionally comprehensive collection, stretching from historical photographs of the nineteenth century to modernist tendencies, such as 'Neues Sehen', 'Straight Photography' and American post-war photography. In 1977 and 1978, respectively, the Tehran Museum of Contemporary Art (TMoCA) hosted the photographic exhibitions "Creative Photography: An Historical Survey"31 and "Pattern of Persia: Roloff Benny photographs 1973-1978”.

28 This agenda had largely been conceived and initiated before World War II by Reza Shah Pahlavi, who had also increasingly funded national art; see, for example, Rizvi 2007. Regarding the cultural politics of the Pahlavi II era (1941-1979), cf. Eimen 2013: 83-90.

29 For a discussion of the state's cultural agenda see Moussavi-Aghdam 2014. The role of the Office of Queen Farah Pahlavi and her patronage of artists is discussed by Diba 2013: 64 .

30 Hamid Notghi had reviewed the exhibition - which included portraits and also photographs of archaeological objects - in Sepid va Siah (black and white), 1965. Maurice Bernard wrote a critique, in which he analysed nine of Shafaeih's portrait photographs. This was published in the 1964 November issue of Photo Ciné Revue and brought Shafaieh to international attention. The article was later translated by Nader Naderpour and published in the magazine Negin in 1965.

31 See Stein 1977. 


\section{A "New" vision: The emergence of fine art photography in Iran}

Born in 1935 in Tabriz, Ahmad Aali had already developed a great affinity for painting during his schooldays and started to practise at the young age of fourteen. Thus, it was very early on that Aali came into contact with prominent painters of Tabriz, such as Ali Akbar Yasami, a student of the academic painter Kamal-al-Molk, and Grigor Vahramian, a graduate of the Moscow School of Painting, Sculpture and Architecture. After graduating from high school in 1952, Ahmad Aali began to study painting, first for a short while at Tehran's School of Visual Arts for Boys and thereafter at the Kamal-al-Molk Art School in Tehran. There, he completed his five years of studies under the tutelage of painters such as Hossein Behzad (1894-1968) and Mahmood Olia' (1902-1962). During this time, Aali developed an interest in European art, in particular the works of painters such as Rembrandt, Jean-François Millet and the Impressionists. $^{32}$

In a recently published monograph, Aali recalls his first encounters with photography, his 'second love'. ${ }^{33}$ There are no better words to describe his intensive self-study than his own:

Prior to becoming familiar with the practical aspects and issues of photography and thus experiencing spectacular physical and chemical feats in the darkroom, for almost two years (since 1958), all I did was browsing photography journals and periodicals such as monthlies and almanacs. I studied all that there was about photography - be it about cameras or the process of work in the darkroom. Every now and then, I went through the books and albums specific to the late 1950s and early 60s. This is how I spent my days and I took interest in analyzing the photos in which I found the forms and compositions to be compatible with the content. That is to say that I assessed the classifications of dark and light and mid-shade values or the levels of white and black and also grey based on the fundaments of visual arts. I would put these photos in a frame that I regarded as most appealing to me. $^{34}$

After two years of extensive theoretical engagement with photography, Aali finally thought the time was right to pick up a camera himself. His first camera

32 Moorizinejad, 2006: 4. For a discussion of Aali's paintings, see Nejadghanbar 2016: 361-364. 33 Ahmad Aali: "I confess that I fell in love three consecutive times: at 14, with painting; at 25, with photography and at 42, with Mina Nouri. The last one complemented the previous two." See Ahmad Aali. Selection of Works 1961-2009, 2010.

34 Mohajer 2016: 369. Translation slightly modified. 
was an Agfa Silette, a model with fixed focal length and without automatic exposure. As the academic study of photography had not yet been established in Iran, Aali sought a thorough exchange with public photographic studios, especially the Studio Universal run by Moharram Arouneh. Through part-time employment in different magazines, he gained access to photo laboratories and came into contact with professional photographers. ${ }^{35}$ This is how Aali finally learned how to produce professional photographs.

Ahmad Aali's oeuvre - encompassing not only photographs, but also paintings - extends over a period of more than five decades. ${ }^{36}$ His artistic career took its course in the late 1950s, when, after graduation, Aali joined "avant-garde" artists that were experimenting with different visual media and made use of various modernist styles, forms and concepts. It is in this context that Aali collaborated with Talar-e Iran. Art spaces like Talar-e Iran were in fact multifunctional sites. As a vital alternative to the cultural institutions of the state, they were "successful social spaces"37 for artistic exchange and theoretical discourses. What is more, they were critical loci for grappling with contemporary artistic positions and for "[giving] art a firmer social footing in Iran". ${ }^{38}$ In an almost arteducational vein they sought to familiarize the public with modern art via artist talks, panel discussions, art classes and lectures. Some art spaces even published pamphlets with introductions to modern art, theoretical essays, exhibition reports and art critiques. During its thirteen years of activity - from 1964 to 1977 - Talar-e Iran hosted 120 art exhibitions, organized discussions and talks, published over 30 books and magazines and translated articles on art criticism, aesthetics and art history. Its third exhibition, held in 1964, was dedicated to photography. ${ }^{39}$ It was organized by Ahmad Aali and the graphic artist and co-founder of the gallery Morteza Momayez (1935-2005), and displayed selected photographs by professional photographers but also by amateurs, artists and architects. ${ }^{40}$

35 Moorizinejad, 2006: 5.

36 The various facets of Aali's oeuvre and his crucial contributions to the artistic sphere through education, pioneering theoretical discourses and far-reaching influences on Iranian contemporary art can only come to light through further research that covers the entire reach of his ongoing artistic work. This article only focuses on the early photographic works of Aali in the context of the emergence of fine art photography in Iran.

37 Farzin 2013: 69.

38 Farzin 2013: 70.

39 The Talar-e Iran group was headed by the architect Mohammad-Reza Jawdat and the painters Mansur Qandriz and Ru'in Pakbaz. See, Farzin 2013: 70. Of the total of 120 exhibitions hosted between 1946 and 1978, Talar-e Iran devoted eleven solely to photography; amongst these was one dedicated to Ahmad Aali in 1965 and one to Bahman Jalali in 1971.

40 These included Sadeq Chubak (1916-1998), Nicole Faridani (born 1935), Mehdi Seifolmolouki, Maryam Zandi (born 1946), Nasser Haghighi, Ebrahim Hashemi, Houshang Caharlou, Hadi 
The exhibited works were heterogeneous and stretched from documentary all the way to creative photography. Notwithstanding, the exhibition was groundbreaking as it was the first time that an art gallery exhibited photographic works.

It was also Talar-e Iran that - in 1965 - published Aali's new "vision" of photography, mapped out in his Manifesto. The topic of fine art photography had first been broached in a few articles from the 1950s; for example, "Is Photography Art?" and "Relationship Between Photography and Painting”. ${ }^{41}$ However, Aali's Manifesto was the first to elaborate an independent aesthetic language for photography. With this text, Aali initiated a crucial discourse on photography as art in Iran, even if this unfolded rather marginally and by no means systematically. The 1960s and 1970s soon saw the publication of further essays and exhibition critiques by writers and art critics, such as Nader Naderpour (1929-2002), Karim Emami (1930-2005) or Javad Mojabi (b. 1942). Furthermore, reviewing photographic exhibitions was established as a firm practice of the press. Although we do not know exactly how Ahmad Aali's plea for a new understanding of photography was received by the cultural and artistic communities of that time, his discussion raised crucial issues about the nature of photography: the relative merits of objectivity versus subjectivity, the uniqueness of art vis-à-vis the reproducibility of photography. Moreover, it opened up themes, such as introducing modernist strategies and techniques to photography and overcoming its fundamental limitations. Aali further elaborated these and other topics in "Photography, Art of our Century", ${ }^{42}$ published in the photo magazine Tasvir in February 1973, as well as in "Photography: A Technique with Artistic Capacities" and "The 'Concern' of Photography is not to Record Nature". These latter texts were published in one of the most influential and popular daily newspapers Ayandegan (The Future People) in February 1977. ${ }^{43}$

The effect of these theoretical discourses about photography, beginning with Aali's Manifesto, was to bring photography closer to contemporaneous artistic currents and thus define it as an artistic medium. Together with photographic exhibitions in art spaces and galleries, this gave a voice to the idea of photography as art. Fine art photography in Iran emerged in the 1960s, at a time

Shafaieh, Moharamm Anoureh, Bahman Jalali (1944-2010) - whose endeavour was central to carrying further the development of Iranian documentary and art photography - and also Ahmad Aali. For a full list of those involved, refer to Hamidian 2007: 94. Aali also recalls the formation of the exhibition in "Conversation with Ahmad Aali" 1997: 471.

41 Motarjemzadeh 2011: 72, 105.

42 Aali 1973.

43 Aali 1977a; Aali 1977b. 
when modernist aesthetic and art forms dominated the artistic movements of period. ${ }^{44}$ This is in sharp contrast to Western fine art photography, which followed the model of painting for decades before it finally drew on its own aesthetic means - as Moholy-Nagy put it in 1927 in his ground-breaking treatise on painting, photography and film: "after the splendorous - though not repeatable - period of daguerreotype, the [Western] photographer tried to imitate all types, styles and manifestations of painting. It took approximately one hundred years until he came to the proper application of his own means." ${ }^{45}$ The emergence of fine art photography in Iran, by contrast, was initially intertwined with modernist aesthetics.

The first solo exhibition of Ahmad Aali's photographic works was hosted in 1963 in Talar-e Farhang (Gallery of Culture). It was made possible through a grant that the Edare-ye honarha-ye ziba (Office of Fine Arts) had founded to support exhibitions by painters, sculptors and graphic artists. This grant was only awarded after ten months of tough negotiations, centring precisely on the question whether photographic work can really be considered art. ${ }^{46}$ Hence, the exhibition propagated photography as an art form not only within artistic trends of that time but also among the official cultural institutions. Accordingly, the exhibition poster states: "With the assistance of the Office of International Relations, as well as the Department of Publications of the Edare-ye honarha-ye ziba” (Figure 4).

44 Moussavi-Aghdam 2014: 6. A discussion of Iranian modernism is beyond the scope of this paper. However, Moussavi-Aghdam states that modernist trends asserted themselves against other art trends in Iran at the end of the 1950s. See Diba 2013 for an introduction to the formation of Iranian modernism and the challenges of the latter in its interaction with the preceding artistic tendencies of the 1940s and 1950s: the academic painting of the Kamal-alMolk school, revival-style arts of the Safavid, and social-realistic art. The first wave of the pioneers of Iranian modernism is discussed by Mojabi 1998: 6-25. For an elaborate discussion on Iranian modernism see Daftari 2002. An overview of the various positions in Iranian modernism is provided in Daftari 2013. Regarding an extensive historiography of modern Iranian art, see Keshmirshekan 2013. Keshmirshekan discusses the issue of Iranian modernism in various other papers, as well.

45 Moholy-Nagy 1927: 46. Author's translation from German. Fine art photography and modernist photographic trends in Iran have been little investigated. Indeed, within the literature on photography as a visual art in Iran, there hardly surfaces any distinction between creative aspects in photography, fine art photography and modernist photography. Similarly, their terminology has barely been addressed thus far. By contrast, the discourse on photography as art in the West generally goes back to the very beginnings of the medium. For an extensive discussion of fine art photography in the nineteenth century and the different styles, cf. Beaumont 1982: ch. 8.

46 Vokhshouri 1991: 34-35. 

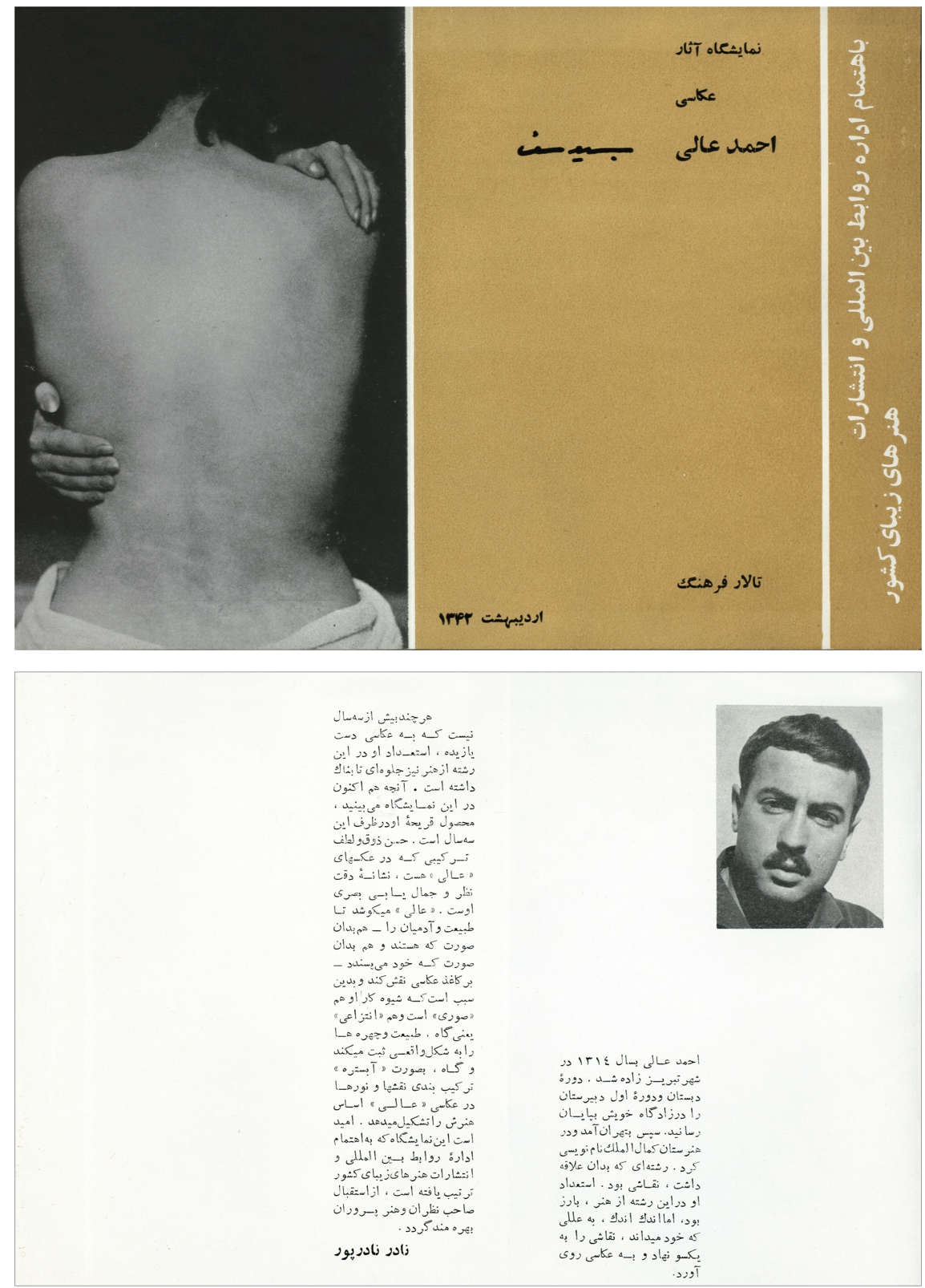

Figure 4: Invitation card for the exhibition at the Talar-e Farhang, Tehran, 1963. 
Aali's exhibition in Talar-e Farhang displayed photographs of landscapes, urban scenes and portraits taken during the years 1961 and 1963. These motifs are, in fact, of the same kind as the landscape and portrait photography that had been established as genres during the 1950s. However, a glance at the composition, experimental pictorial solutions and personal expression in Aali's exhibited works suffices to recognize substantive differences. Consider, for example, the photograph Fasham (1961) (Figure 5). Together with Tehran (1962) and Portrait of Mansour Ghandriz (1963), Aali considers Fasham to be among the most important works of this exhibition. ${ }^{47}$ Like many other landscapes from Aali's early works, the photograph is bound up with the zeitgeist in using a symbolic language rooted in contemporaneous Persian literature. In Fasham, the vitality of nature is suffocated by immobility, the materiality of the trees is hidden behind a veil of illusion. The close-knit interweaving of the trees places the emphasis upon form over content so much so that nobody asks why the trees are seemingly petrified or why they lack a crown. On a symbolic level, Aali alludes to the social reality of his day, where only form and not content, surface not depth, is paid any attention to. More

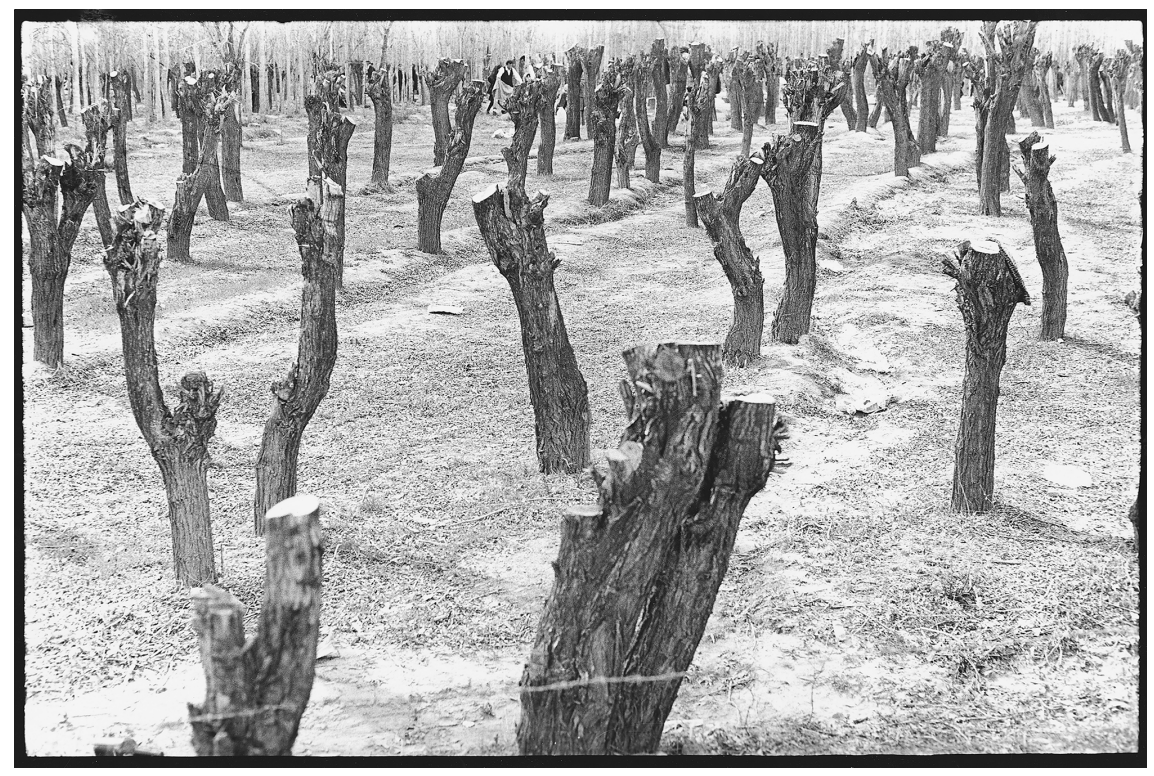

Figure 5: Ahmad Aali, Fasham, 1961, silver gelatin print, courtesy of the artist.

47 Email communication with Ahmad Aali, 23 May 2016. Some of the photographs exhibited in Talar-e Farhang, including the landscapes of Zarband, Fasham, the work At the Grave of Qom, and Portrait of Mansour Ghandriz, were published in Aali 2010: 43, 44-45, 63, 118, 69. 
important, however, is the aesthetic novelty thereby introduced: Aali purposefully used a close-up shot to dissolve the image centre. The emerging boundlessness of space compels the beholder to a new way of seeing, one that lies in the realm of the subjective. Aali's artistic strategies, like using close-ups, transforming perspectival rules, and incorporating the structural lines of nature, manifest the transition from established conventions to an artistic conception of photography.

In 1965, the gallery Talar-e Iran hosted a solo exhibition of photographic works that Aali took during his numerous journeys through Iran in 1963 and 1964. Tabriz (1965) (Figure 6), an important work from this exhibition, ${ }^{48}$ is paradigmatic of the experimental techniques Aali developed during this period. This photograph is reminiscent of the fundamental principles of the movement 'Neues Sehen': unusual crops of images, diagonal perspectives, unconventional compositions with unexpected projections on the surface of the picture plane, and light-shadow contrasts. In an interview, Aali describes how he had composed image constructions on the basis of "subjective seeing-experiences" prior to his journeys. He then sought for the lines, forms and structures in nature and urban landscapes that would materialize these visions of composition, display, detail and image structure. At times, he had to be patient till he came across optimal conditions, waiting, that is, for components such as compositional elements, light and shadow, and grey shadings to conform to his subjective construct: the outside follows the inside. ${ }^{49}$ The aim of this synthesis of the objective and the subjective was not to transmit some specific message. Rather, "insofar as they transport anything at all, then it is such a very general phenomenon as optical or rather photographic perception, i. e. human sight and the possibility of its extension or modification by the camera" ${ }^{50}$ Gerhard Glüher described in these terms the creative phase of photography at the Bauhaus ${ }^{51}$ and his words are equally apt to capture Aali's transition to a modernist conception of photography.

48 Email communication with Ahmad Aali, 23 May 2016. Amongst the other most significant works of the artist is the photographic series Mahmoud Abad. Other photographs from this exhibition, such as Bushahr (1965), Portrait of Mansour Ghandriz (1963), Tabriz (1965), were published in Aali 2010: 80, 131, 148 (respectively).

49 In the interview, the artist provides invaluable clues to his approach to the motifs depicted during this period of his artistic endeavours. See Vokhshouri 1991: 31. See also "Conversion with Ahmad Aali” 1997: 477.

50 Translated from German by this author. First cited by Wick 1991a: 21.

51 It is important to note that the photography movement at the Bauhaus did not have a uniform style. Wick, for example, speaks of photography at the Bauhaus (Fotografie am Bauhaus) to denote photographic styles that were consistent with the most fundamental principles of the Bauhaus. See Wick 1991a: 10-12. 


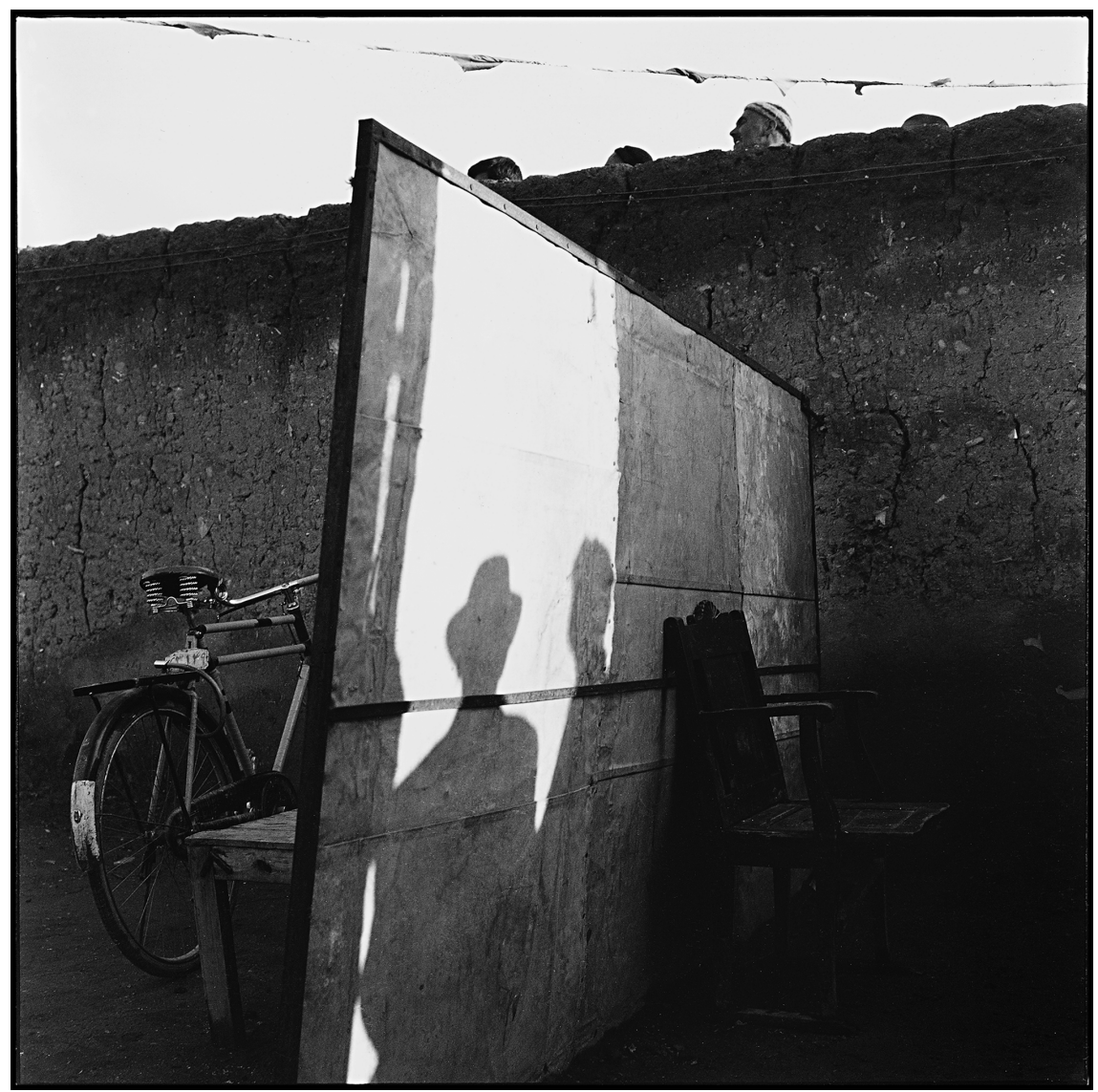

Figure 6: Ahmad Aali, Tabriz, 1965, silver gelatin print, courtesy of the artist.

Aali's next solo exhibition was hosted at the Borghese Gallery in Tehran in 1967. It primarily featured portrait photographs of intellectuals, social activist and modernist artists, which Aali took between 1962 and 1966. In these photographs Aali departed from conventional forms and recent trends, like the use of soft focus and lighting in portraits. Instead, he drew on modernist techniques in photography. For example, in the portrait of Mohammad-Reza Jodat, Architect, Painter (1965) (Figure 7) Aali uses multiple exposures to blend the hands with the upper face, and especially the eyes. This creates the effect of a transcendent plane: a view through the hand into an endless distance that ingeniously alludes to Jodat's profession as a painter and architect. In this manner, Aali points 


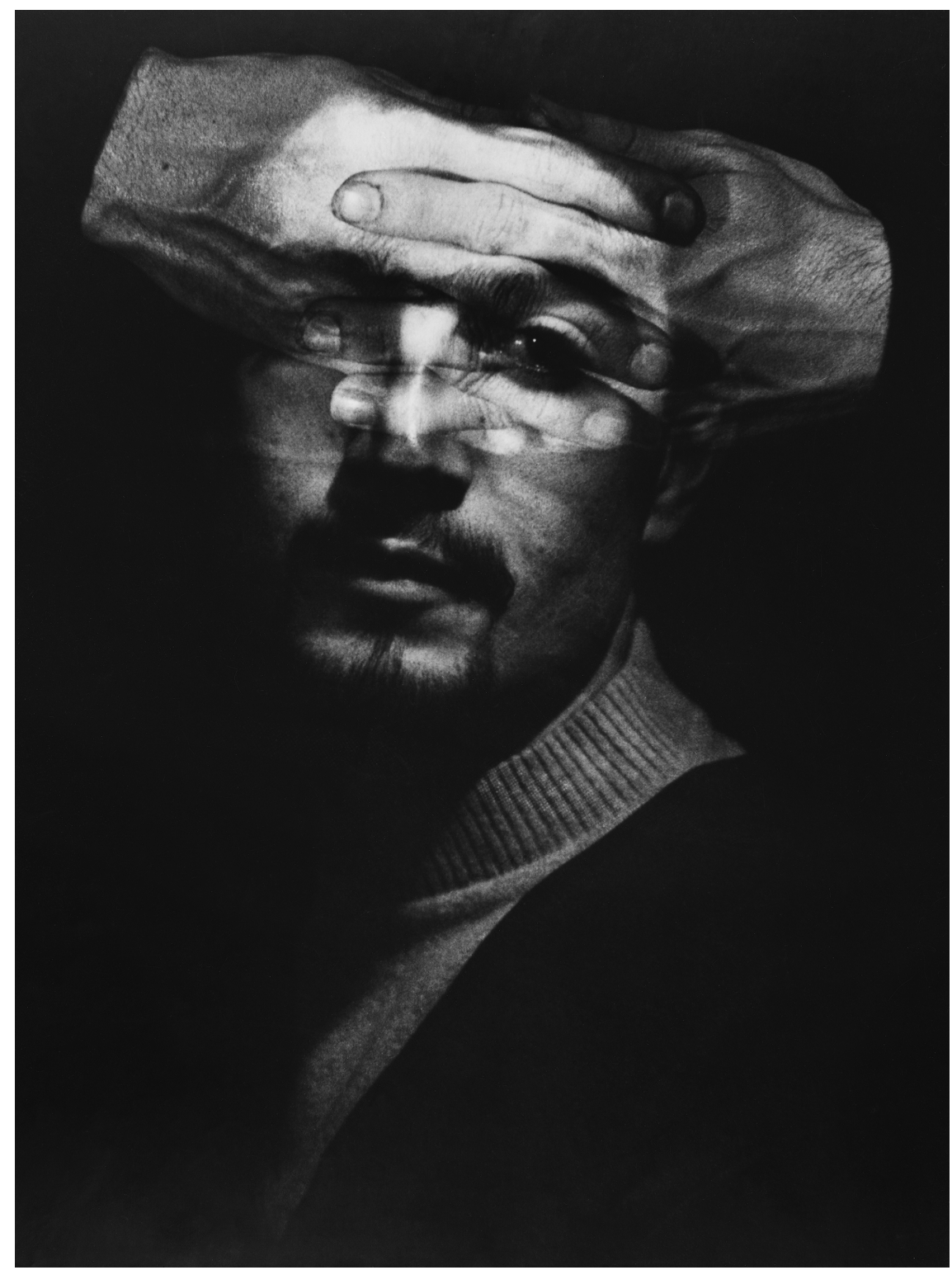

Figure 7: Ahmad Aali, Mohammad-Reza Jodat, Architect, Painter, 1965, silver gelatin print, courtesy of the artist. 
beyond the visible exterior of the sitter towards Jodat's seeing: the inner vision, which Jodat materialized on canvasses or architectural sketches. Aali himself names the portrait Changiz Shahvaq, Painter, Sculptor (1965) (Figure 8) as one of the most significant of the exhibition. ${ }^{52}$ There, Aali evokes a similar contemplative layer by playing around with proportions and skewed perspectives. He places Shahvaq's hand in the foreground as the site of artistic creation, that with which the sculptor translates his inner vision into forms. By using such techniques as multiple exposures and extreme compositional effects, Ahmad Aali breaks through the externally visible and thus uncovers the inner person of the sitter. In the other exhibited works, Aali further experiments with textures and fractures, as he combines portrait photographs with everyday objects in photo installations, applies negative-positive effects in the juxtaposition of two images, and uses methods of collage and photo montage.

In his solo exhibition at the gallery Seyhoun (Seihoun) in 1968, Aali presented a comprehensive selection of his works that reveal the multitude of photographic concepts and forms he had hitherto developed (Figure 9). ${ }^{53}$ There, Aali also for the first time exhibited a composite photograph: Tehran (1968) (Figure 10). Aali first conceived the potential of "mosaic photograph" - as he calls them - because of nothing more than an optical coincidence:

I do recall that in those early years, while I was editing printed samples of the photographs of my trip to the south of Iran, the photos fell on the ground and got scattered. Some of the photos were turned upside-down. These white touches created an interesting and attractive geometric form and composition among the photos on the ground and amidst their black and grey colors. A new image was born through changing the setting of the white touches. This event was of course effective in the move towards photomontage, photo collage, and generally photography. In my view, this is the prime advantage and the potential for photography: it allows a subjective and objective continuity to be launched in photography thereby raising a new idea to be heard. I took and continue to take extensive advantage of this issue in the process of constructing my mosaics. ${ }^{54}$

At first glance, some of Aali's serial images, e. g. series of hands, bear analogy to the serial photographs of, for instance, the German artist Kurt Kranz (1910-1997). Kranz began his experiments with serial images during the 1930s and is first and foremost

52 Email communication with Ahmad Aali, 23 May 2016.

53 This comprehensive selection included the photographs Fasham 1961, Masjed Soleyman 1963, Dezful 1967, and Kalardasht 1967, which are published in Aali 2010: 44-5, 148, 60-61, 149 (respectively).

54 Mohajer 2016: 366-367. Translation slightly modified. 


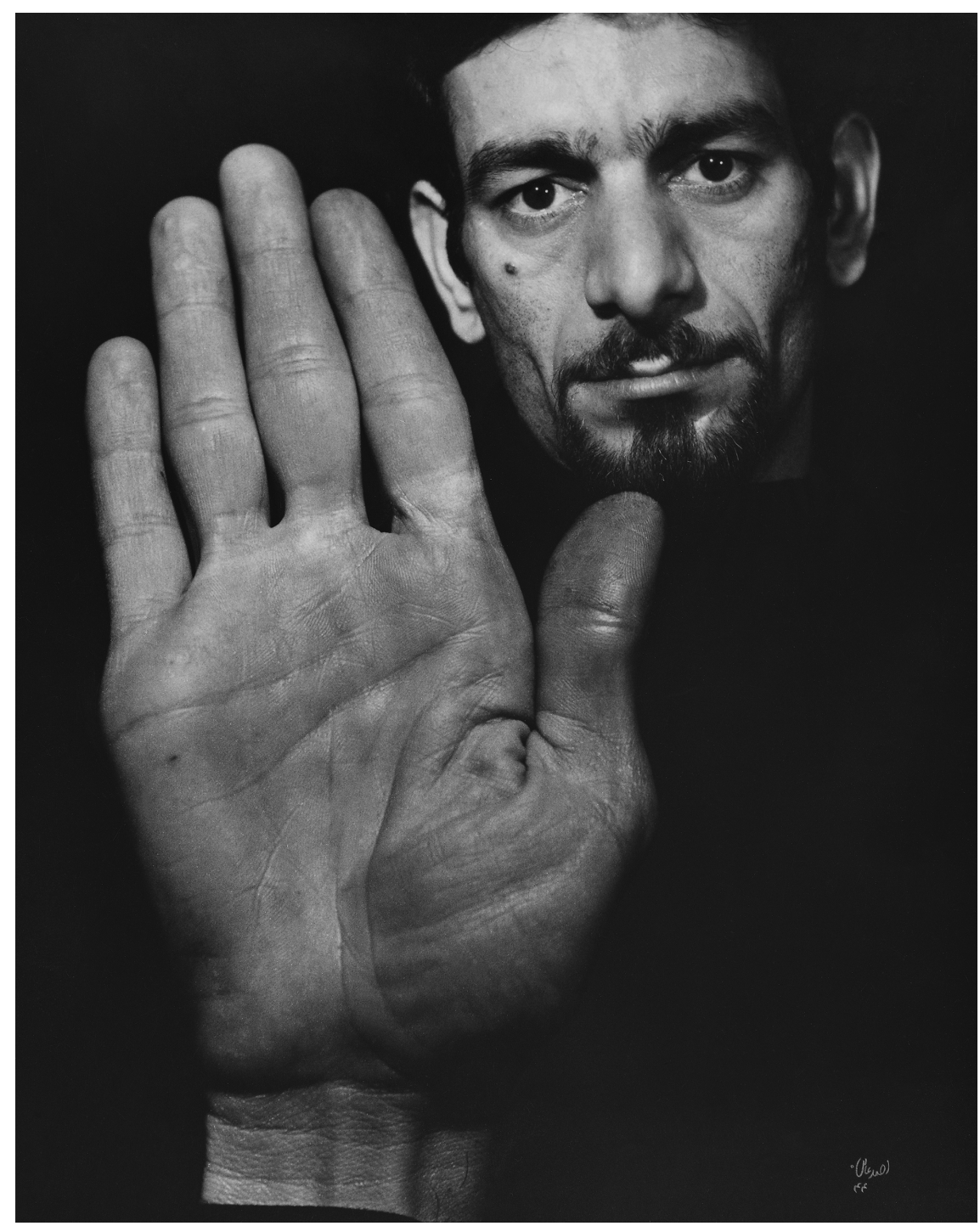

Figure 8: Ahmad Aali, Changiz Shahvaq, Painter, Sculptor, 1965, silver gelatin print, courtesy of the artist. 


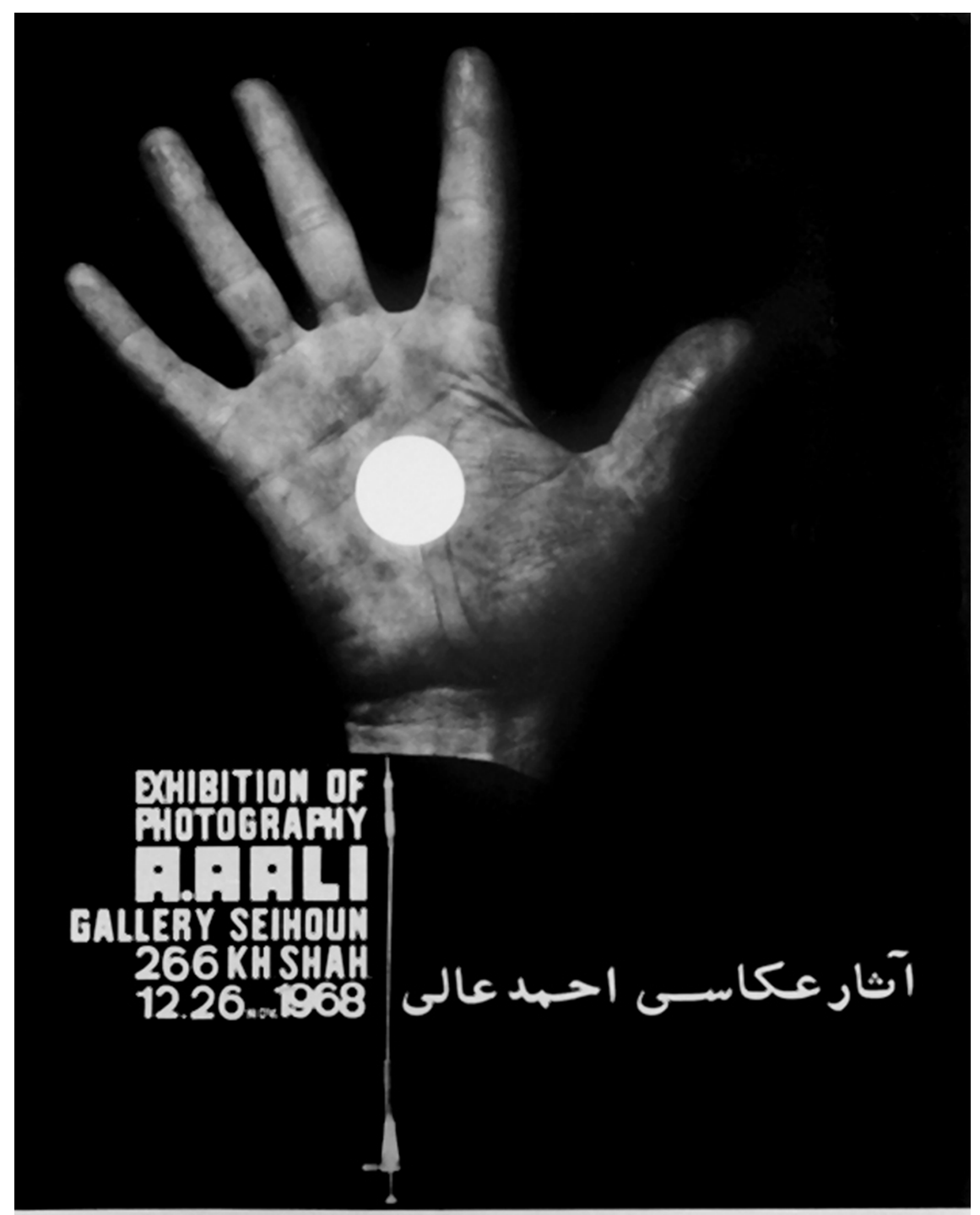

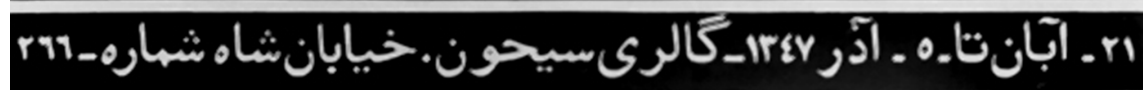

Figure 9: Poster of the exhibition at the Gallery Seyhoun, Tehran, 1968. 


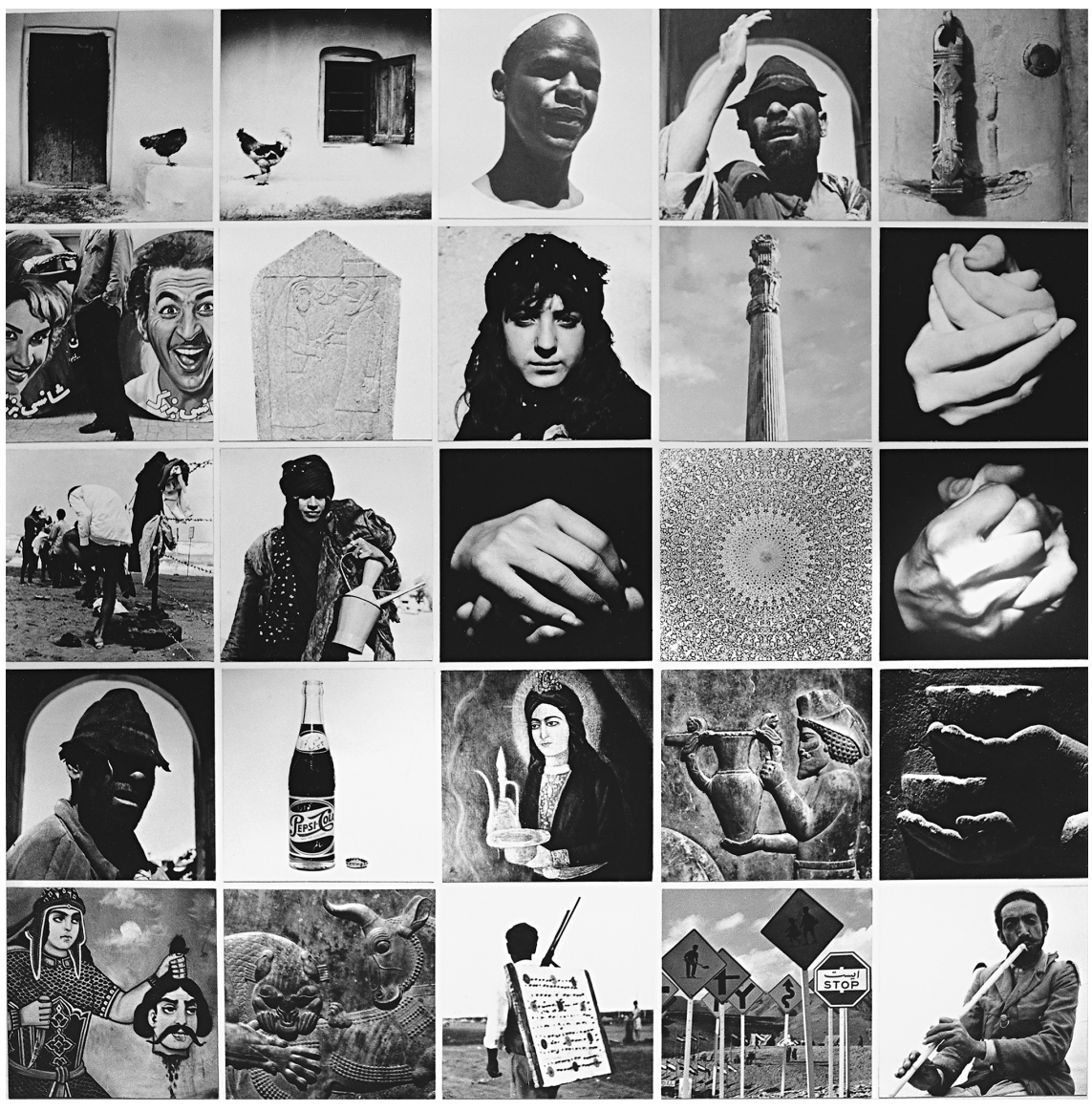

Figure 10: Ahmad Aali, Tehran, 1968, silver gelatin print, courtesy of the artist.

renowned for his series of mimics and gestures. Kranz's series are such that "the individual image is not in itself meaningful; instead it has a transitory and subordinated character in that it is merely a link in the chain of the whole". ${ }^{55}$ In contrast, the composite photographs of Ahmad Aali are at once fragmentary and unitary. The individual images retain their autonomous legibility but they can equally well be perceptually discarded. Because of this plurality the visual

55 Wick 1991b: 149-150. Translated from German by this author. Even though Rainer Wick evokes these words in describing Kranz's serial works from 1925, this characterization applies just as well to his later serial photographs. 
experience of the composite is essentially dynamic and progressive, evoking a transitory flux from the individual part to the infinite whole.

In 1970, the French Cultural Society in Tehran devoted a solo exhibition to Ahmad Aali. It displayed an array of Aali's photographs that seek to conceptualize the natural forms and lines of the human body and its movements. The run of solo exhibitions of Aali's photographic works during the formative decades for fine art photography in Iran culminated in 1977, when official cultural organs invited Ahmad Aali to present his photographic works amidst those of prominent modernist artists at the exhibition "Iranian Modern Art" hosted at the Wash Art - International Art Fair in Washington, D.C. (Figure 11). ${ }^{56}$ There, Aali exhibited the installation Self-Portrait (1964), in which he shows that photography can be extended into three-dimensionality.
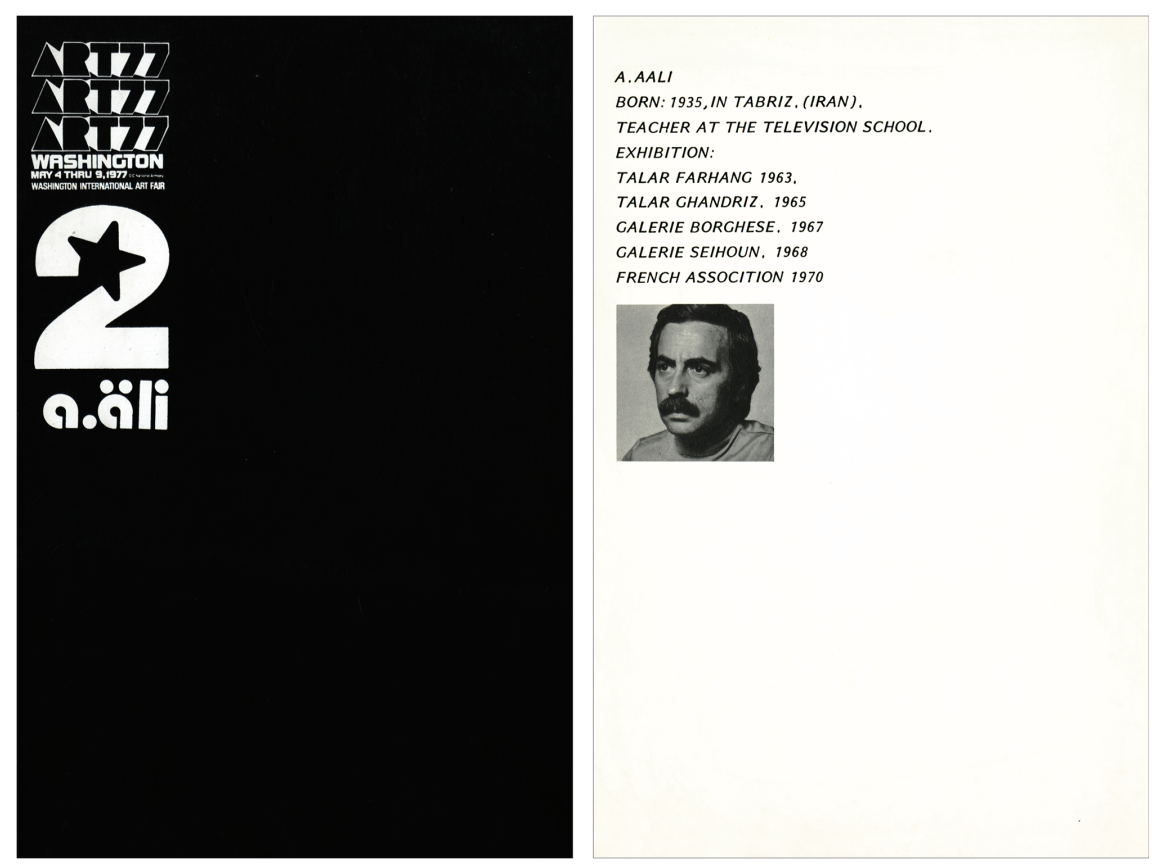

Figure 11: Wash Art - International Art Fair in Washington, DC, 1977.

56 Vokhshouri 1991: 36. Ahmad Aali recalled how a few photographic works had been selected for exhibitions of Iranian contemporary art at the international scale. He saw this as a cornerstone of success, a sign that photography was being recognized as an artistic medium in the cultural-political landscape. 
Fereshteh Daftari argues that the image can be read as a metaphorical expression of political suffocation. ${ }^{57}$ Another important work first displayed at this international exhibition was the photomontage Tehran (1976) (Figure 12). This work consists of eight photographs of a flight of steps, and passers-by, taken at different times in a public park in Tehran. These photographs are so arranged as to constitute a pillar that vertically reaches through the visual space. Because of the overarching composite form, the individual images are no

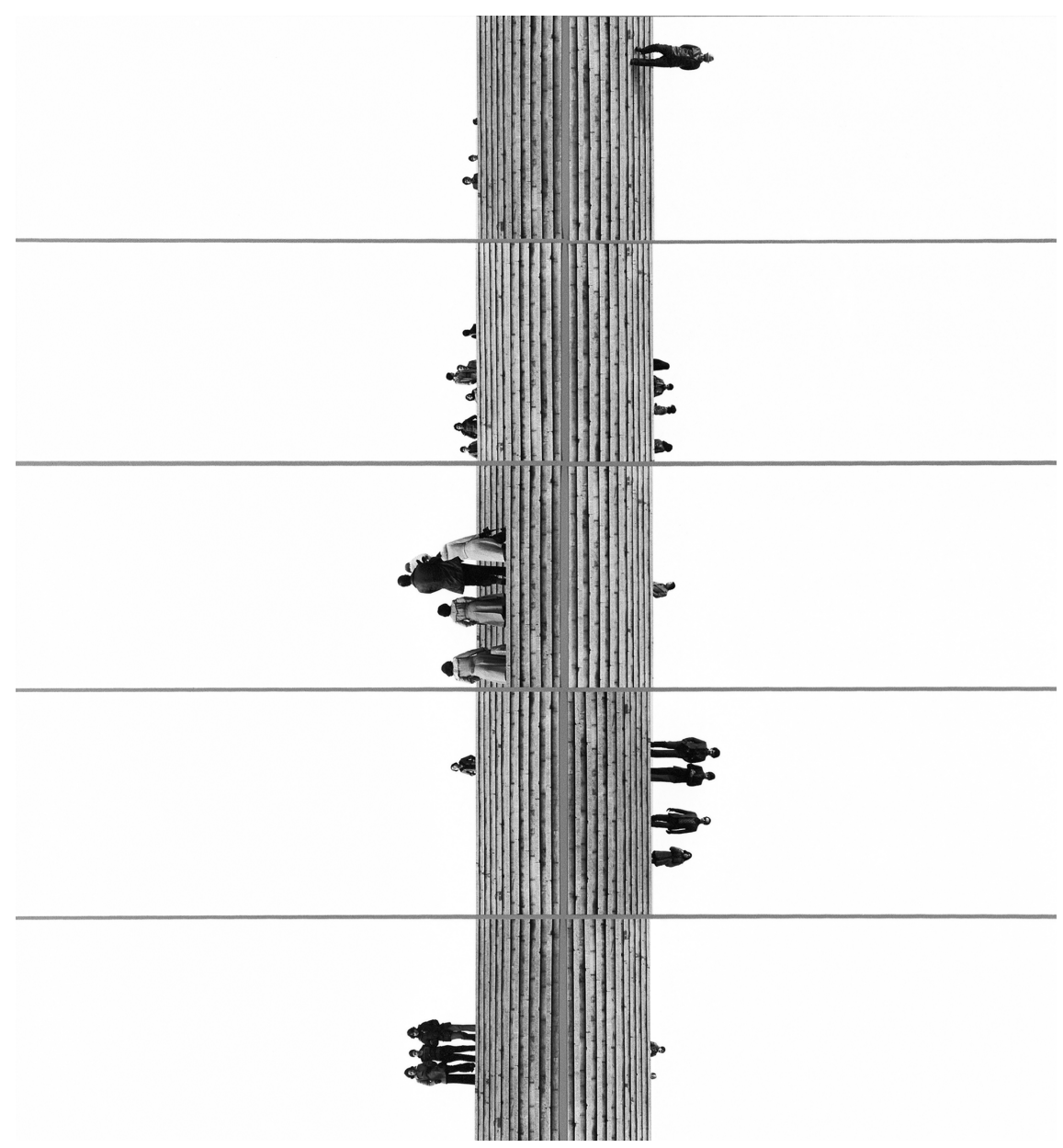

Figure 12: Ahmad Aali, Tehran, 1976, silver gelatin print, courtesy of the artist.

57 Daftari 2013: 40. 
longer of any import and the visual experience is instead dominated by the rhythm of the linear connexions and iteration of the interweaving forms. This creates the sense that the horizontal passers-by are floating in limbo. Aali thereby evokes a spatial-temporal continuity and, in Mojaher's inspiring words, "entwine[s] geography and history". ${ }^{58}$

The early photographic works of Ahmad Aali demonstrate how the artist had experimented with aesthetics and applied modernist artistic strategies to photography to elaborate an autonomous aesthetic language. Discussing these works tracks the photographic concepts that were central to the emergence of fine art photography in Iran during the 1960s and 1970s. In this period, so productive and critical for Iranian photography, fine art photographers defined, as Hamid Severi states, a "language of modernism in Iran. This shares some similarities with European experimental modernism and late American modernism."59 Severi briefly outlines some of the artistic strategies pursued by Iranian fine art photographers: photomontages and collages, manipulated and painted negatives, hand-tinted black-and-white prints, abstract and semi-abstract photography, photography without a camera, and assembled photomontages and collages; and, finally, the sequential, composite, and constructed photographs of Ahmad Aali. ${ }^{60}$ However, Aali went beyond the influences of modernist tendencies and independently developed novel photographic concepts.

\section{A conceptual turn: Photographic concepts of time and space}

The photograph Mahmoud Abad (1964) (Figure 13), shown in Talar-e Iran in 1965, is the first exhibited example of the novel photographic concepts of space and time that Aali developed in his serial photographs. As such, it reveals Aali's innovative approaches to overcoming the 'static realism' and de facto limitations of the medium in respect to the representation of spatial and temporal dimensions: photography seems unable to move beyond the singularity of a spatial perspective and the static nature of a temporal snapshot. Instead of restraining himself to one spatial-temporal perspective, Aali compiles sets of images in various ways. At times, he puts two images of the same space next to one another horizontally. The images are either taken from different perspectives,

58 Mohajer 2016: 365.

59 Severi 2013: 99.

60 Severi 2013: 99-100. 

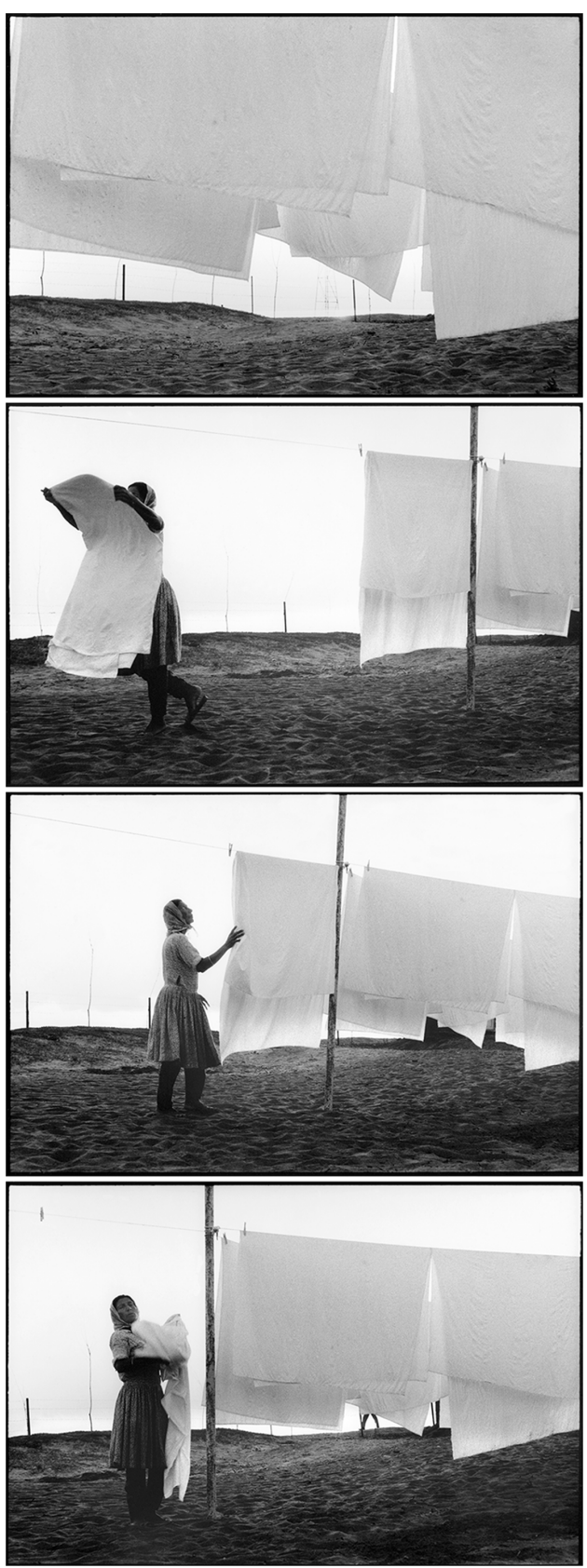

Figure 13: Ahmad Aali, Mahmoud Abad, 1964, silver gelatin print, courtesy of the artist. 
evoking a perceptual transformation of space (Figure 14), or else show different scenes spread over the passing time. At other times, Aali compiled several photographs in horizontal or vertical series or as an ensemble. Like his double images, these series create the impression of the extension of space. Aali's serial images sometimes commence or conclude with a void space, such as a white surface. The images of his series can stand on their own or be complemented with further images ad infinitum; what persists is the overarching unity evoked in the whole. This unity is expressed visually in overlapping time-space spheres, which create the appearance of an infinite spatial and temporal seeing. This transgresses, both conceptually and formally, the 'static realism' of photography and opens up a subjective layer.
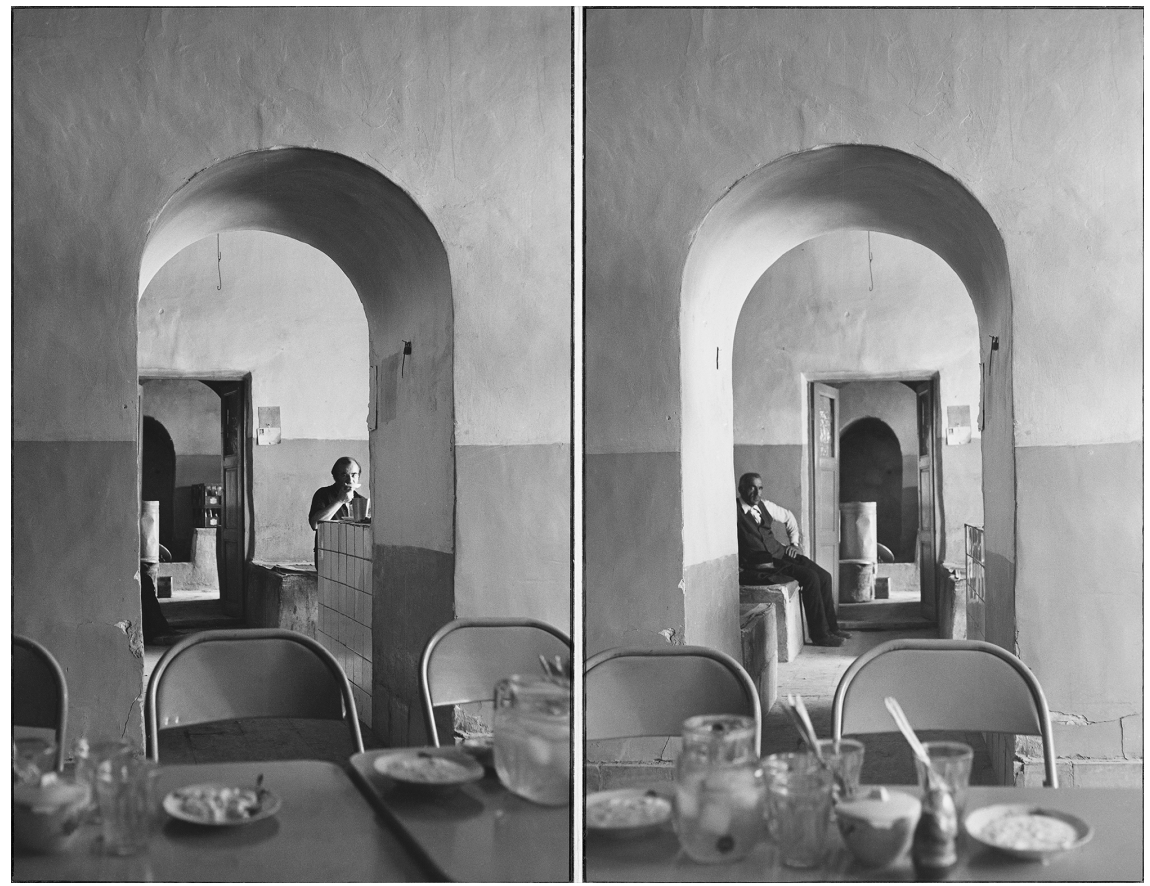

Figure 14: Ahmad Aali, Ghodratabad (Damghan), 1974, silver gelatin print, courtesy of the artist.

The practice of taking serial or sequential photographs had first appeared in the 1880s in the works of the physiologist Étienne Jule Marey (1830-1904) and the photographer Eadweard Muybridge (1846-1907). However, it was only in the 1930s with the Bauhaus movement that this practice overcame the seemingly 
inevitable 'static realism' of photography. There emerged sequential photographs that attempted to incite illusions of complex, constructed rather than two-dimensional spaces. ${ }^{61}$ At the Dessau Bauhaus, Kranz produced photo sequences with hand gestures, and expressions of the face, mouth and eyes. His Prinzip Seriell describes a mode of production whereby every individual image submits to a cycle, "a process of extracting one image from another". ${ }^{6}$ This sequential addition of photographs fundamentally transformed visual phenomenology from the experience of a single image to a dynamic way of seeing. Kranz's works went largely unheeded until the emergence of conceptual art and body language in the 1960s and 1970s. ${ }^{63}$

In the 1940s and 1950s, photojournalists William Eugene Smith (1918-1978) and Leonard McCombe (born 1923) carried the Prinzip Seriell forward in using series of photographs to report events. This practice of visual narration added a new philosophical, allegorical and surreal layer in the 'story-telling' of Duane Michals (born 1932). In seeking to address his own personal and psychological questions, Michals found that he first had to transcend the limitations inherent in a single image. In 1966, he therefore started to create what he called "photo stories", starting with his first photographic sequence, a five-part image called The Woman is Frightened by the Door (1966) first exhibited at the Underground Gallery in New York in 1968. ${ }^{64}$ Almost as if he were a home moviemaker, Michals carefully selected actor(s) and staged a setting to tell visual stories of the spirit, of mortality, desire, human relationships, politics, time and memory. ${ }^{65}$ In this way, Michals gave birth to the narrative sequences that were so ground-breaking for the history of photography.

Ahmad Aali experimented with the technique of sequential photographs at about the same time, albeit independently and, to his own regret, completely unaware of Duane Michals's works. ${ }^{66}$ Aali's sequences, Tehran (1978) (Figure 15) for example, are to some extent comparable to those of Duane Michals, who

61 Walter Gropius (1883-1969), for example, called for sequence photographs for the purpose of architectural representations.

62 Wick 1991b: 154

63 Wick 1991b: 162. For a discussion of the photographic works of Kranz and the emergence of photo sequences refer to Wick 1991b.

64 Bailey 1975: 27.

65 Bailey 1975: 22. For further information about the use of photographic sequences for 'storytelling' see among others Livingstone (1997): 7-14.

66 “Conversation with Ahmad Aali”, 1997: 482. 

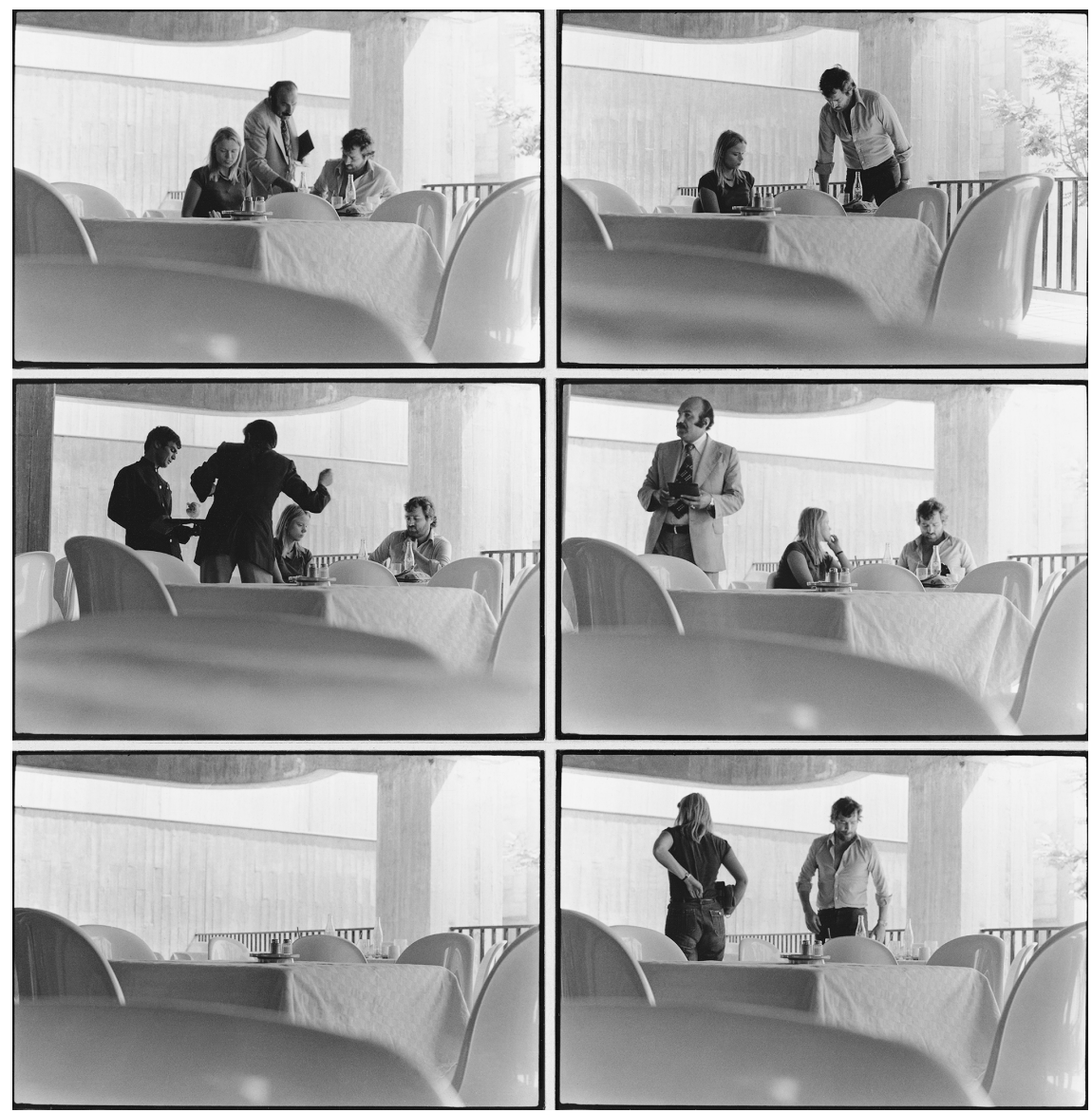

Figure 15: Ahmad Aali, Tehran, 1978, silver gelatin print, courtesy of the artist.

composed sequences primarily to tell a linear story. In his sequential photographs, Aali was rather concerned with the concept of seeing and combining objective reality with the realm of the subjective. He was fascinated by the visual capacity to abstract overarching forms and lines from collocated and adjacent photographs. This not only forces the depicted objects into the background but, in fact, almost diffuses the individual photographs. Drawing on this capacity, Aali extracts the essence of conceptual art in sequential photographs such as Mahmoud Abad: for the representation becomes autonomous in respect of the represented, the forms and lines in respect of the object. This transports the beholder, who no longer sees a single image representing a fragment of reality, but now has a view of a 
whole. The viewers is transported, in short, "from micro to macro", as Aali so forcefully puts it. ${ }^{67}$ In provoking subjective experiences, the composite image creates a dynamically changing reality:

The work I have produced accordingly up to this day have been in the form of a painting made of combining from two to 100 images in an original and one-copy format; I have used the rhythm and sequence of form in attributing meaning to their content. I also used full frame square and rectangular photos in these works and, at times, the multiplication of one photo alongside each other would create a singular work. At other times they cause a different objectification of various scenes of attributing meaning through mental rhythm, relation, composition, and form. I have sometimes put the photos edge by edge and with no gap and at times with a gap and it is these distances which determine the positive or negative mindset and allow the audience a free hand in stitching or not the gaps with respect to the content of the image. ${ }^{68}$

The visual extension of time and space in serial photographs and the concomitant extension of the subjective experience of time and space manifests itself in multifarious ways in Aali's photographic works from the 1960s and 1970s: for example, as Mehran Mojaher explains, in restricting time to momentary intervals, in capturing time as an indication of human activity as in Kalate Mollat (1974) (Figure 16), in erasing time and space through an opaque background, and in how "space and time intertwine [to] indicate the process of artistic action" 69 as in Abbas Bolukifar (1973) . This latter photo sequence was inspired by the 1966 movie Blow-Up by Michelangelo Antonioni (1912-2007), an adaption of a short story by Julio Cortazár. In Abbas Bolukifar, Aali combines the principles of enlargement with the sequential composition of photographs, revealing noteworthy parallels with the photographic sequence Things Are Queer, created in the very same year, 1973, by Duane Michals. ${ }^{70}$ Like Michals, Aali creates a bounded cycle by commencing and completing the sequence with the same photograph. In Abbas Bolukifar, Aali frames images within other images to create a spatial iteration, an encapsulation of spaces in one another. Through the connection of the forms and lines within the encapsulated images he shows how every individual detail is, in fact, part of an all-encompassing whole. This makes for the infinite flux of transition that inevitably pulls one into the endless cycle from the fragmentary to the whole and back again.

67 Interview with Ahmad Aali, 2010. Aali took care to emphasize his intention of transmitting seeing from micro to macro and back again.

68 Mojaher 2016: 367.

69 Mohajer 2016: 367.

70 Weinberg 1996: 11-14. 

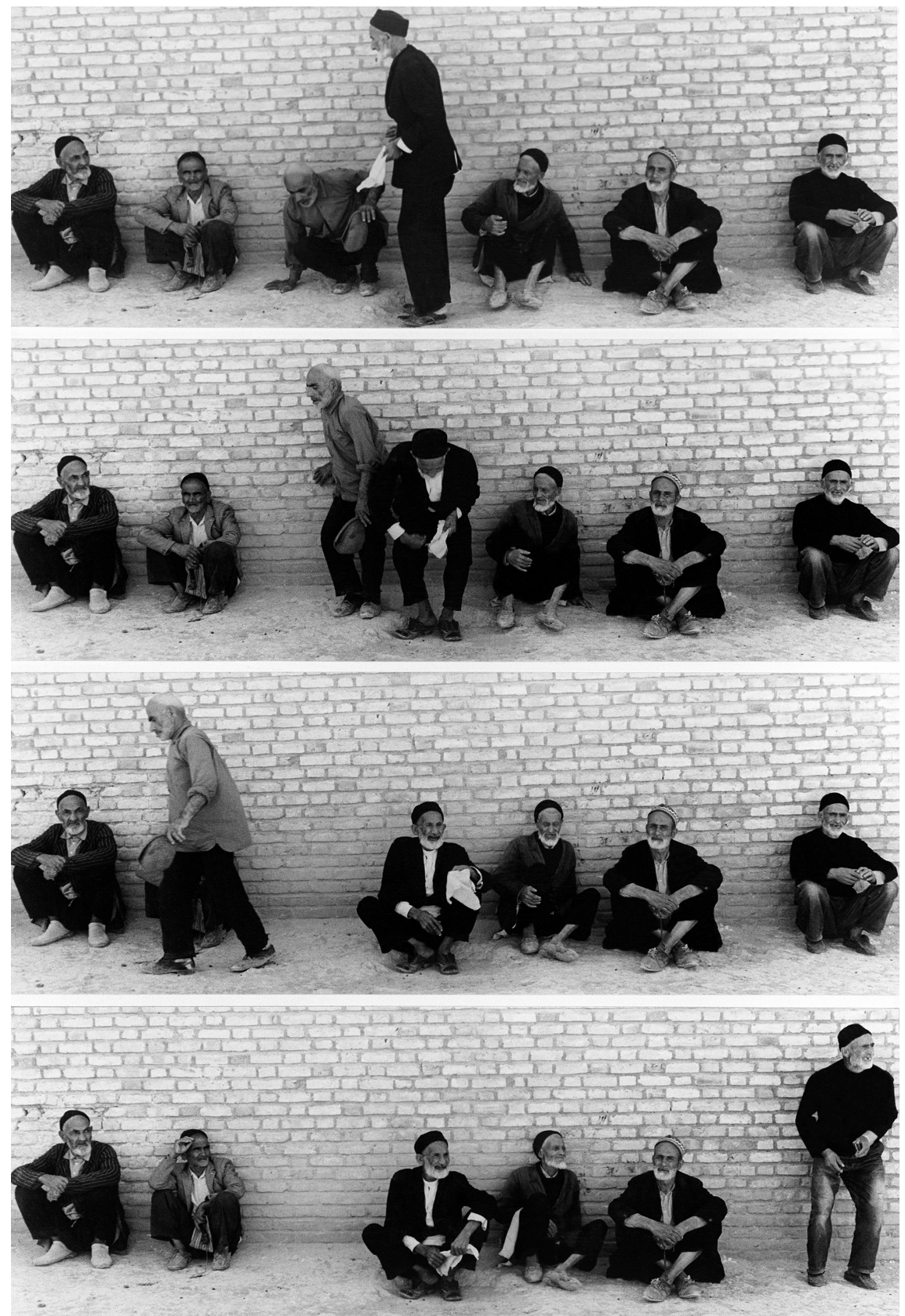

Figure 16: Ahmad Aali, Kalate Mollat, 1974, silver gelatin print, courtesy of the artist. 


\section{Concluding remarks: Marks in history}

In 1997, in the context of a discussion on the emergence of Iranian fine art photography and its further development the internationally renowned Iranian photographer Kaveh Golestan (1930-2003) referred to Ahmad Aali as "the only photographer and the lonely photographer". ${ }^{71}$ In this way, Golestan underscores the mark that Aali has forever imprinted on the history of photography in Iran. For Aali dissociated photography from an understanding that had dominated the first hundred and twenty years of its history in Iran: namely, photography as a technical tool for remembering, recording and documenting. Aali enforced his new "vision" of a medium that transcends its purely mechanical operation and accordingly promoted the founding of fine art photography in a multitude of ways. ${ }^{72}$ In 1965, he submitted the first theoretical discourse on photography as an art form - his Manifesto - in which he put forward a distinctive aesthetic language for photography; a language in which the objective forms, lines and elements of nature intertwine with the subjective thoughts, sensations and perceptions of the artists. Further, Aali initiated and organized the first exhibitions in art spaces and art galleries and thus grounded fine art photography within the cultural spheres and artistic movements of the 1960s and 1970s.

Ultimately, it is Aali's early works themselves that demonstrate his quest for artistic forms of expression in photography. They are exemplary of the formation of fine art photography and the modernist aesthetic that developed in Iranian photography at the time. In independently experimenting with the ins and outs of the photographic medium, its restrictions and potentialities, Ahmad Aali developed his own conceptual solutions in sequential photographs. Through collocation and adjacency in serial images, he evokes transitory cycles between the fragmentary images and their whole. In the interplay between the objectivity of external reality and subjective sensibilities, the image is in dynamic transition. The overlapping space-time spheres create the appearance of an infinite spatial and temporal seeing. Aali's photographic concepts of time and space reveal divergences from but also parallels with other spheres of fine art photography, and should be accorded their full autonomy and uniqueness in the (re-) writing a narrative of art history.

71 Golestan 2002: 60.

72 Here, I draw on Livingstone’s statement that “Outstanding photographers [....] have consistently maintained the transcendence of their vision over the purely mechanical operation of their medium.” See Livingstone 1997: 7. 
Acknowledgements: I wish to express my gratitude to the artist Ahmad Aali for various interviews and for answering my further questions in emails. He provided invaluable information on his artistic oeuvre and profound insights into his fascinating thoughts and concepts. Moreover, I am much obliged that the artist so generously and helpfully shared substantial amounts of material from his own archives, to which I would have hardly had access otherwise, but which proved so vital to this article. My sincere thanks go to Mina Nouri for her companionship and all her kind assistance in my research on Ahmad Aali, and to Yahya Dehghanpour and Mehran Mohajer for sharing their knowledge on the modern history of photography in Iran. My thanks extend to Touraj Hamidian and Ramiar Manouchehrzadeh for making several unpublished scripts available to me, and to Donna Stein for kindly answering my queries about the photographic collection of the TMoCA. I am grateful to Silvia Naef (Geneva), Nadia Radwan (Berne) and Abbas Daneshvari (Los Angeles) for their valuable comments. My heartfelt thanks go to Daniel Helbig for his encouragement and all his multifarious assistance.

\section{Bibliography}

Aali, Ahmad (1965): Introductory Text (Untitled). Exhibition Catalogue. Tehran: Talar-e Iran (Persian).

Aali, Ahmad (1973): “'Akāsi, honar-e 'asr-e mā” [Photography, Art of our Century]. Tasvir 9: 2-3 (Persian).

Aali, Ahmad (1977a): “'Akāsi: fan-i bā binesh-e honari” [Photography: A Technique with Artistic Capacities]. Ayandegan 9: 8 (Persian).

Aali, Ahmad (1977b): “'Mozou'-e' 'aks sabt-e tabi't nist” ['Concern' of Photography is Not to Record Nature]. Ayandegan 9: 8 (Persian).

Aali, Ahmad (2010): Selection of Works 1961-2009. Tehran: Nazar Art Publication.

Aali, Ahmad (2016): Selection of Paintings and Photographs 1953-2014. Tehran: Nazar Art Publication.

Bailey, Ronald H. (1975): The Photographic Illusion: Duane Michals. Los Angeles: Thomas Y. Crowell Company.

Beaumont, Newhall (1982): The History of Photography: From 1839 to the Present Day, 5th edition. New York: The Museum of Modern Art.

Behpoor, Bavand (2014): 'Introduction to 'The Nightingale's Butcher Manifesto' and 'Volume and Environment II"'. ARTMargins 3.2: 118-128.

Bonetti, Maria Francesca / Prandi, Alberto / Mohammadi Nameghi, Khadijeh (2013): "The First Hundred Years of Iranian Photography: A Bibliography". The First Hundred Years of Iranian Photography. Special issue of History of Photography, 37.1. Edited by Reza Sheikh and Carmen Pérez Gonzáles, 126-134.

Campany, David (ed.) (2005): Kunst und Fotografie. Berlin: Phaidon Verlag. 
“Conversation with Ahmad Aali” (1997): Kelk Magazine, October 1996-January 1998, nos. 80-83: 466-503 (Persian).

Daftari, Fereshteh (2002): “Another Modernism: An Iranian Perspective”. In: Picturing Iran. Art, Society and Revolution. Edited by Shiva Balaghi and Lynn Gumpert. London: I.B. Tauris, 39-88.

Daftari, Fereshteh (2013): “Redefining Modernism. Pluralist Art before the 1979 Revolution”. In: Iran Modern. Edited by Fereshteh Daftari and Layla S. Diba. New York: Asia Society Museum, 25-43.

Diba, Layla S. (2013): "The Formation of Modern Iranian Art. From Kamal-al-Molk to Zenderoudi”. In: Iran Modern. Edited by Fereshteh Daftari and Layla S. Diba. New York: Asia Society Museum, 45-66.

Eimen, Alisa (2013): "Shaping and Portraying Identity at the Tehran Museum of Contemporary Art (1977-2005)". In: Performing the Iranian State: Visual Culture and Representations of Iranian Identity. Edited by Staci Gem Scheiwiller. London: Anthem Press, 83-100.

Farzin, Media (2013): “A Short History of Art Exhibitions in Iran, 1946-78”. In: Iran Modern. Edited by Fereshteh Daftari and Layla S. Diba. New York: Asia Society Museum, 67-71.

Golestan, Kaveh (2002): “Nour, sāyeh, sāyeh roshan” [Light, Shade, Silhouette]. Herfeh: Honarmand 3: 60 (Persian).

Grigor, Talinn (2009): Building Iran: Modernism, Architecture, and National Heritage Under the Pahlavi Monarchs. New York: Periscope Publishing.

Hamidian, Turaj (2007): “Ba'd az Qājāryyeh” [After Qajars]. Herfeh: Honarmand 18.4: 82-103 (Persian).

Hamidian, Turaj (2010): “I Want to Intervene in Nature and its Realities”. In: Ahmad Aali. Selection of Works 1961-2009. Tehran: Nazar Art Publikation, 240-246.

Helbig, Elahe (2016): “From Narrating History to Constructing Memory: The Role of Photography in the Iranian Constitutional Revolution”. In: Iran's Constitutional Revolution of 1906 and the Narratives of the Enlightenment. Edited by Ali Ansari. London: Gingko Library (forthcoming).

Jalali, Bahman (1998): Ganj-e pydā. Majmu'e-i az 'akshā-ye ālbomkhāne-ye kākh-e Golestān [Visible Treasure. A Collection of Photographs from Album Khaneh Golestan Palace Museum]. Tehran: Cultural Heritage Organization (Persian).

Keshmirshkan, Hamid (2013): “Historiography of Modern Iranian Art”. In: Iran Modern. Edited by Fereshteh Daftari and Layla S. Diba. New York: Asia Society Museum, 17-23.

Koschatzky, Walter (1993): Die Kunst der Photographie. Technik, Geschichte, Meisterwerke. Wien: Neuer Pawak Verlag.

Kries, Mateo / Kugler, Jolanthe (eds.) (2015): Das bauhaus: \#allesistdesign. Weil am Rhein: Vitra Design Museum.

Livingstone, Marco (1997): “'The Sensual Duane Michals': Photographer of Things Unseen”. In: The Essential Duane Michals. Edited by Duane Michals and Marco Livingstone. London: Thames and Hudson.

Manouchehrzadeh, Ramyar (2008): Rouykardi bar 'akāsi-ye honari ba'd az enghelāb - Tehran [Review on Fine Art Photography after the Revolution - Tehran]. MA thesis. Tehran: University of Art, Applied Arts Faculty (Persian).

Mohajer, Mehran (2016): "Seeking Ahmad Aali". In: Ahmad Aali. Selection of Paintings and Photographs 1953-2014. Tehran: Nazar Art Publikation, 365-370.

Moholy-Nagy, László (1927): Malerei, Fotografie, Film. Bauhausbücher 8. Munich: Albert Langen Verlag. 
Moholy-Nagy, László (1927): Malerei, Fotografie, Film. Bauhausbücher 8. Munich: Albert Langen Verlag.

Mojabi, Javad (1998): Pioneers of Contemporary Persian Painting. First Generation. Translated by Karim Emami. Tehran: Iranian Art Publishing.

Motarjemzadeh, Mohammad Khodadadi (2011): Tahlil-e kārkardhā-ye farhangi-honari-ye 'akāsi dar Iran (panjāh sāl-e akhir) [Analysis of Cultural-Artistic Functions of Iranian Photography (in recent fifty years)]. Ph.D. diss. Tehran: University of Art, Applied Arts Faculty (Persian).

Motarjemzadeh, Mohammad Khodadadi (2013): “Photography in the Grey Years (1920-40)". Translated by Reza Sheikh. The First Hundred Years of Iranian Photography. Special issue of History of Photography, 37.1. Edited by Reza Sheikh and Carmen Pérez Gonzáles, 117-125.

Moussavi-Aghdam, Combiz (2014): “Art History, 'National Art' and Iranian Intellectuals in the 1960s". Dynamics in the Middle East and North Africa. Special issue of British Journal of Middle Eastern Studies 41.1: 132-150.

Nejadghanbar, Behzad (2016): “Ahmad Aali: The Painting Photographer”. In Ahmad Aali. Selection of Paintings and Photographs 1953-2014. Tehran: Nazar Art Publikation, 361-364.

Nelson, Robert S. (1997): “The Map of Art History”. The Art Bulletin 79.1: 28-31.

Rizvi, Kishwar (2007): "Art History and the Nation: Arthur Upham Pope and the Discourse on 'Persian Art' in the Early Twentieth Century". Muqarnas: Journal of Islamic Art and Architecture 24: 45-65.

Severi, Hamid (2013): “A Remarkable Oversight: Iranian Art Photography of the 1960s and 1970s”. In: Iran Modern. Edited by Fereshteh Daftari and Layla S. Diba. New York: Asia Society Museum, 97-101.

Sheikh, Reza (2010): "National Identity and Photographs of the Constitutional Revolution". In: Iran's Constitutional Revolution: Popular Politics, Cultural Transformations and Transnational Connections. Edited by H.E. Chehabi and Vanessa Martin. London: I.B. Tauris, 249-276.

Stein, Donna (1977): Creative Photography: An Historical Survey. Exhibition Catalogue. Tehran.

Tahmasbpour, Mohammad Reza (2013): “Photography in Iran: A Chronology”. Translated by Reza Sheikh. The First Hundred Years of Iranian Photography. Special issue of History of Photography, 37.1. Edited by Reza Sheikh and Carmen Pérez Gonzáles, 7-13.

Vokhshouri, Ahmad (1991): "Pishkesvatān-e 'akāsi: Ahmad Aali” [Pioneers of Photography: Ahmad Aali]. 'Aks Magazine 4.11: 31-41.

Weinberg, Jonathan (1996): “Things are Queer”. Art Journal 55.4. Special Issue We're Here: Gay and Lesbian Presence in Art and Art History: 11-14.

Wick, Rainer K. (1991a): “Mythos Bauhaus-Fotografie”. In: Das Neue Sehen. Von der Fotografie am Bauhaus zur Subjektiven Fotografie. Edited by Rainer K. Wick. Munich: Klinkhardt \& Biermann, 7-32.

Wick, Rainer K. (1991b): “Kurt Kranz. Malerei, Fotografie, Film”. In: Das Neue Sehen. Von der Fotografie am Bauhaus zur Subjektiven Fotografie. Edited by Rainer K. Wick. Munich: Klinkhardt \& Biermann, 145-166. 